\title{
One-pot Synthesis of Amphiphilic ABC Triblock Copolymer PEO-b-PEHOx-b-PEtOz and its Self-Assembly into Nanoscopic Asymmetric Polymersomes
}

\author{
Davy Daubian ${ }^{1}$, Alexandra Fillion ${ }^{1}$, Jens Gaitzsch ${ }^{1,2, *}$ and Wolfgang Meier ${ }^{1, *}$ \\ ${ }^{1}$ Department of Physical Chemistry, University of Basel, Mattenstrasse 24a, BPR 1096, 4058 Basel, \\ Switzerland \\ ${ }^{2}$ Leibniz-Institut für Polymerforschung Dresden e.V., Hohe Strasse 6, 01069 Dresden, Germany \\ E-Mail: gaitzsch@ipfdd.de (J.G.),wolfgang.meier@unibas.ch (W.M.)
}

\section{For Table of Contents use only}

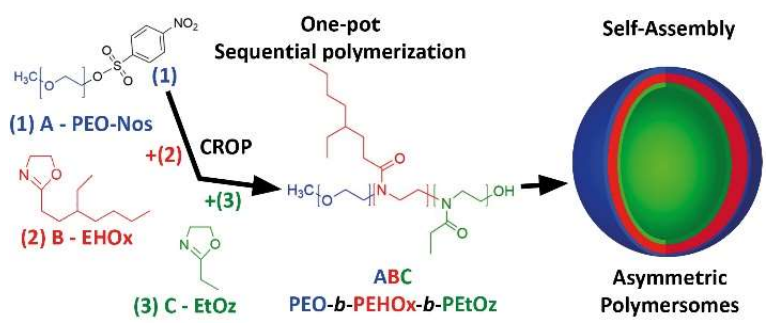

\section{Abstract}

We report the efficient one-pot synthesis of a new biocompatible amphiphilic $A B C$ triblock terpolymer: Poly(ethylene oxide)-block-poly(2-(3-ethylheptyl)-2-oxazoline)-block-poly(2-ethyl-2oxazoline) (PEO- $b$-PEHOx- $b$-PEtOz) using sequential microwave-assisted polymerization. Depending on the hydrophilic weight fraction of the terpolymers, nanoscopic micelles, worms and polymersomes were formed as well as multicompartment vesicles. The self-assemblies were thoroughly analysed regarding their size and shape using dynamic and static light scattering, TEM and Cryo-TEM. By varying the ratio of PEO to PEtOz, we were able to drive the asymmetry of the polymersome membranes and proved it by two independent methods, BCA assay and 2D- ${ }^{1} \mathrm{H}-\mathrm{NOESY}$ NMR, which confirmed the presence of a longer PEO block (45 units) and the absence of a shorter PEtOz (less than 32 units) on the outer surface of the polymersomes. Thus, from this new family of $A B C$ triblock terpolymers, asymmetric polymersomes with a thin membrane $(6-10 \mathrm{~nm})$ can be obtained, justifying a potential use in biomedical applications with the directed insertion of transmembrane proteins. 


\section{Introduction}

Nature is a treasure trove of elaborate structures assembled from different bio(macro)molecules. One of those structures is the lipid bilayer, which forms the membrane around living cells, but also within them to construct cellular compartments based on lipid vesicles or liposomes. During the last decades, elaborating mimics of cell membranes from lipids, proteins and polymers have attracted significant interest especially in biomedical fields, like drug delivery or catalytic nanocompartments. ${ }^{1-7}$ Artificial membranes self-assembled from amphiphilic block copolymers, are particularly interesting as these polymersomes show several advantages compared to liposomes. They exhibit an improved chemical and physical stability and a lower membrane permeability than liposomes since the thickness of their membrane can be engineered by modulating the molecular weight of the hydrophobic block. By changing the species and the lengths of individual segments of the block-copolymer, polymersomes can be functionalized and their membrane properties can be controlled and modulated. ${ }^{8-10}$ Most of the polymersomes investigated are obtained from $A B$ diblock and $A B A$ triblock copolymers (with $A=$ hydrophilic and $B=$ hydrophobic block). The resulting polymersomes have a symmetric $A B / B A$ bilayer membrane from diblock copolymers or an ABA monolayer membrane from triblock copolymers membrane, hence the same inner and outer leaflet. ${ }^{11}$ However, this does not mimic one of the core characteristic of biological membranes: its asymmetry, which is expressed by the lipid composition, substitution and distribution. This characteristic is essential for the insertion and orientation of membrane proteins e.g. proton pumps and similar vectorial molecules. ${ }^{12-13}$ It has been shown that the insertion of membrane proteins into symmetric artificial membranes leads to the loss of their preferred orientation and by extension to the loss of their function. ${ }^{14}$ To overcome this issue, some studies attempted to break the symmetry of artificial membranes by tailoring the chemical composition of the internal and external leaflet of the vesicle. ${ }^{15-16} \mathrm{~A}$ more straightforward strategy to obtain asymmetric polymeric membranes is by self-assembly of asymmetric amphiphilic $A B C$ triblock terpolymers (with $C=2^{\text {nd }}$ hydrophilic block), which will be shortened to "ABC triblocks" in this manuscript. In order to obtain asymmetry, both hydrophilic blocks (A and C) should be different in 
size. Following spacial arguments, the longer hydrophilic segments segregate towards the outer leaflet due to a larger radius (curvature) and reduced steric hindrance whereas the smaller segments tend to remain on the inner leaflet the polymersome membrane. Therefore, for polymersomes from an $A B C$ triblock where $A$ is longer than C, A is predominantly on the outside while $C$ is inside (Figure 1 ). ${ }^{17-19}$

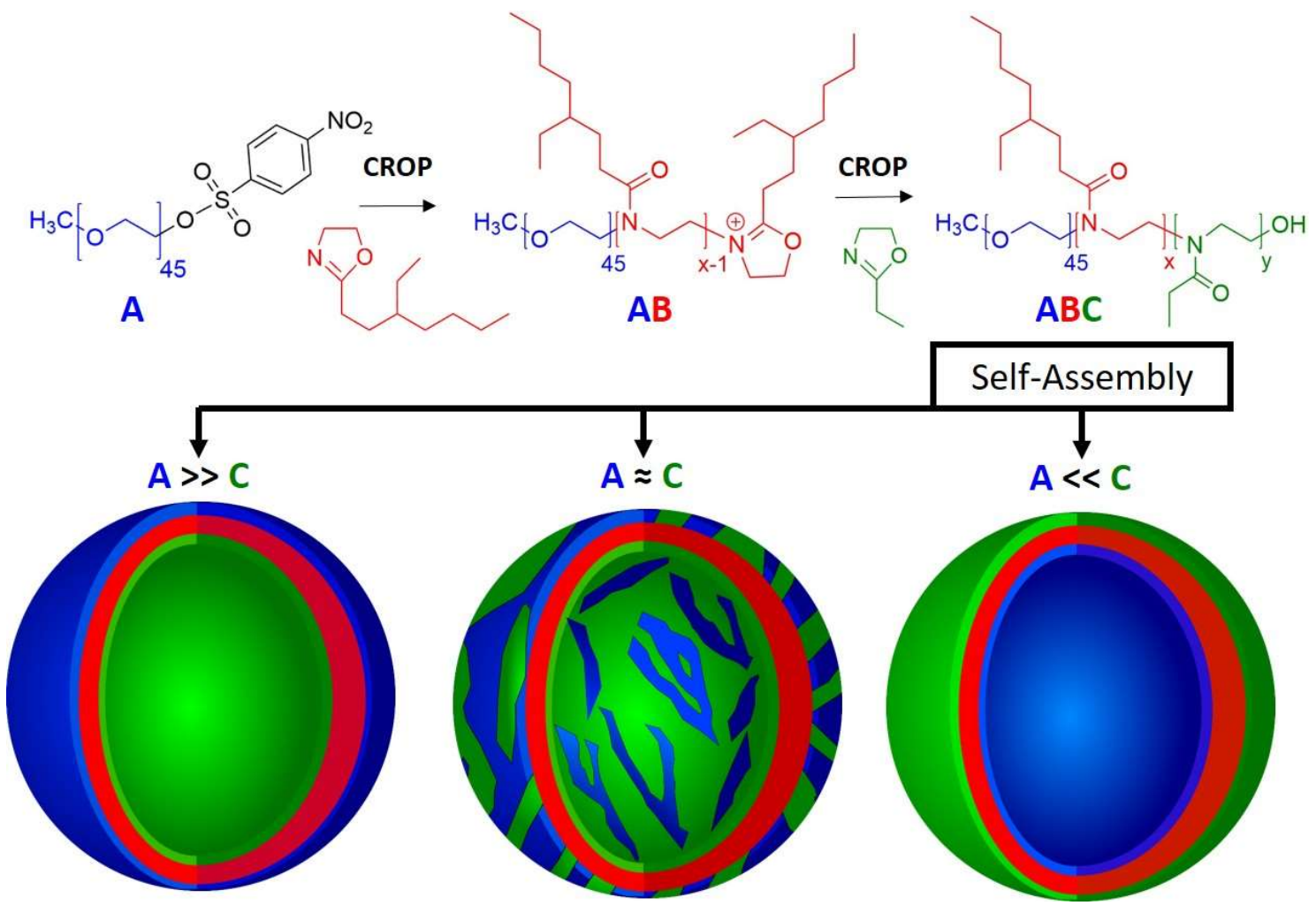

Figure 1 - Schematic representation of the synthesis of poly(ethylene oxide)-block-poly(2-(3ethylheptyl)-2-oxazoline-block-poly(2-ethyl-2-oxazoline) (PEO-b-PEHOx-b-PEtOz) and the resulting possible membrane orientations of the polymersomes formed by self-assembly.

Until now, only a few studies have reported the synthesis of such ABC triblock terpolymers. ${ }^{17,20-25}$ In most cases their syntheses are complex procedures as they involve the combination of different polymerization techniques. It means that intermediate products must be purified and sometimes endgroups need to be modified to serve as initiator for the next step. In order to reduce the number of synthetic steps, an interesting alternative is the use of sequential polymerization. In this approach, the same polymerization technique is employed to polymerize the monomers one after the other. Once a monomer is fully consumed, the polymerization continues with the next one in suitable conditions. It is a powerful stategy to obtain various $A B C$ triblocks, for example poly(2-oxazolines) using the living 
character of cationic ring-opening polymerization (CROP). ${ }^{26-29}$ The $A B C$ triblock targeted in this paper continues our previous works on ABC triblocks: PEO- $b$-PDMS- $b$-PMOXA ${ }^{19}$ and PEO- $b$-PCL- $b$-PMOXA ${ }^{17}$, mainly replacing PDMS with poly(2-(3-ethylheptyl)-2-oxazoline) (PEHOx). The amphiphilic AB diblock copolymer PEO- $b$-PEHOx ${ }^{30}$ already showed the great potential of PEHOx for self-assembly due to its branched side chain and is the basis for this work.

Herein, we present the one-pot synthesis of a novel amphiphilic $A B C$ triblock terpolymer consisting of biocompatible blocks: Poly(ethylene oxide)-block-poly(2-(3-ethylheptyl)-2-oxazoline)-block-poly(2ethyl-2-oxazoline) (PEO-b-PEHOx-b-PEtOz). Starting from our previously published PEO-Nos macroinitiator (block A), PEHOx (block B) and PEtOz (block C) were added using sequential CROP ${ }^{30}$. A library of $A B C$ triblocks with different PEHOx and PEtOz block lengths was obtained and their selfassembly was studied in depth. Depending on both PEHOx length and hydrophilic weight fraction (f), different self-assembly morphologies were obtained via film rehydration and characterized intensively. A combination of dynamic and static light-scattering (DLS/SLS), transmission electron microscopy (TEM) and cryogenic transmission electron microscopy (Cryo-TEM) analysis proved the formation of a variety of nanoscale structures, notably polymersomes. Using two independent methods, namely bicinchoninic assay (BCA) and $2 \mathrm{D}-{ }^{1} \mathrm{H}-\mathrm{NOESY} N M R$, the surface composition of the polymersomes from the self-assembled $A B C$ triblocks was thoroughly characterized.

\section{Experiment section}

\section{Materials}

Glassware for polymerization was dried overnight at $120^{\circ} \mathrm{C}$ prior to use. Deuterated chloroform $\left(\mathrm{CDCl}_{3}\right)$ and water $\left(\mathrm{D}_{2} \mathrm{O}\right)$, Isopropanol, 2-ethylhexyl bromide, n-butyllithium, $N, N^{\prime} N^{\prime}, N^{\prime}$ tetramethylenediamine (TMEDA), triethylamine, $p$-nitrobenzenesulfonyl chloride, methyl $p$ toluenesulfonate chloride, anhydrous chlorobenzene, 2-methyl-2-oxazoline, 2-ethyl-2-oxazoline, 
barium oxide, poly(ethylene oxide) monomethyl ether (PEO, $2000 \mathrm{~g} \cdot \mathrm{mol}^{-1}$ ) and a bicinchoninic acid assay kit, were obtained from Sigma-Aldrich $(\mathrm{CH})$ and used as received. 2-methyl-2-oxazoline and 2ethyl-2-oxazoline was distilled over barium oxide $(\mathrm{BaO})$ and stored under argon. Poly(ethylene oxide) monomethyl ether (PEO, $\left.2000 \mathrm{~g} \cdot \mathrm{mol}^{-1}\right)$ was dissolved in water and then lyophilized. Milli-Q water (18.2 $\mathrm{M} \Omega \mathrm{cm}$ ) was used from a Purelab Option-R 7/15 system (ELGA LabWater, UK). Anhydrous dichloromethane (DCM), tetrahydrofuran (THF) and acetonitrile were obtained from an inert solvent purification system PureSolv MD 5 (Inert, USA).

\section{Microwave-assisted synthesis}

Microwave polymerization was conducted on a Biotage Initiator System (Biotage, Sweden) equipped with Robot Eight. The microwave synthesizer operated at a constant set temperature (mentioned in results and discussion) monitored by the Infrared (IR) sensor.

\section{Synthesis of 2-(3-ethylheptyl)-2-oxazoline (EHOx)}

The monomer was prepared by using the synthetic procedure described previously ${ }^{30-31}$ Briefly, TMEDA (10.32 mL, $69 \mathrm{mmol}, 1 \mathrm{eq}$ ) was dissolved in $300 \mathrm{~mL}$ THF at $-78^{\circ} \mathrm{C}$ under Ar. N-butyllithium (2.5M in hexane, $26 \mathrm{~mL}, 65 \mathrm{mmol}, 0.96 \mathrm{eq}$ ) was then added and after $60 \mathrm{~min}$ stirring, 2-methyl-2-oxazoline (5.8 $\mathrm{mL}, 68 \mathrm{mmol}, 1 \mathrm{eq}$ ) was added. The stirring was continued for 2 hours at $-78^{\circ} \mathrm{C}$ and were concluded by the addition of 2-ethylhexyl bromide $(10.13 \mathrm{~mL}, 57 \mathrm{mmol}, 0.83 \mathrm{eq})$. The solution was allowed to warm to room temperature overnight and was then terminated after $25^{\circ} \mathrm{C}$ with $150 \mathrm{~mL}$ of methanol and the solvents were evaporated under reduced pressure. The residue was dissolved in $200 \mathrm{~mL}$ of a biphasic solution 1:1 $\mathrm{CHCl}_{3} / \mathrm{NaHCO}_{3}$ (sat). The aqueous phase was extracted twice with $75 \mathrm{~mL}$ of chloroform. The combined organic phases were washed with water and brine. After drying over $\mathrm{MgSO}_{4}$, the solvent was removed under reduced pressure, and the crude product was purified by distillation. The purified product was confirmed to be EHOx by ${ }^{1} \mathrm{H}$ NMR. It was then stored under argon atmosphere. ${ }^{1} \mathrm{H}$ NMR $\left(500 \mathrm{MHz}, \mathrm{CDCl}_{3}, 295 \mathrm{~K}, \delta, \mathrm{ppm}\right): 0.86\left(\mathrm{~m}, 6 \mathrm{H}, \mathrm{CH}_{3}\right), 1.27\left(\mathrm{~m}, 9 \mathrm{H}, \mathrm{CH}\left(\mathrm{CH}_{2} \mathrm{CH}_{3}\right)\right.$ $\left.\mathrm{CH}_{2} \mathrm{CH}_{2} \mathrm{CH}_{2} \mathrm{CH}_{3}\right), 1.60\left(\mathrm{~m}, 2 \mathrm{H}, \mathrm{NCOCH}_{2} \mathrm{CH}_{2}\right), 2.25$ (t, J=8.2 Hz, $\left.2 \mathrm{H}, \mathrm{NCOCH} \mathrm{CH}_{2}\right), 3.82(\mathrm{t}, \mathrm{J}=9.5 \mathrm{~Hz}, 2 \mathrm{H}$, 
$\left.\mathrm{CNCH}_{2}\right), 4.2\left(\mathrm{t}, \mathrm{J}=9.4 \mathrm{~Hz}, 2 \mathrm{H}, \mathrm{COCH}_{2}\right) .{ }^{13} \mathrm{C} \mathrm{NMR}\left(500 \mathrm{MHz}, \mathrm{CDCl}_{3}, 295 \mathrm{~K}, \delta, \mathrm{ppm}\right): 10.7,14.1\left(\mathrm{CH}_{3}\right), 25.5$, 25.6, 28.8, 29.3, 32.3, $38.9\left(\mathrm{CH}_{2}\right), 54.3\left(\mathrm{CNCH}_{2}\right), 67.2\left(\mathrm{COCH}_{2}\right), 169.8\left(\mathrm{CNCH}_{2}\right)$.

\section{Synthesis of PEO-Nos macroinitiator}

The macroinitiatior was prepared by using the synthetic procedure described by Daubian et $a l^{30}$ Poly(ethylene oxide) monomethyl ether (PEO, $\left.2000 \mathrm{~g} \cdot \mathrm{mol}^{-1}\right)(4.00 \mathrm{~g}, 2 \mathrm{mmol}, 1 \mathrm{eq})$ was dissolved in 80 $\mathrm{mL}$ dry $\mathrm{DCM}$, chilled to $0{ }^{\circ} \mathrm{C}$. Triethylamine $(2.8 \mathrm{~mL}, 20 \mathrm{mmol}, 10 \mathrm{eq})$ and $p$-nitrobenzenesulfonyl chloride $(4.43 \mathrm{~g}, 20 \mathrm{mmol}, 10 \mathrm{eq})$ were then added. The reaction was allowed to stir for $10 \mathrm{~h}$ at $0{ }^{\circ} \mathrm{C}$ under argon atmosphere. The reaction mixture was then concentrated under vacuum and the high excess of unreacted reagents was then extracted 3 times with $400 \mathrm{~mL}$ of isopropanol at RT exploiting the poor solubility of PEO at RT in Isopropanol. It was then placed into a dialysis membrane (regenerated cellulose, MWCO $3.5 \mathrm{kDa}, \mathrm{RC6}$, Spectra Por, USA)) and dialyzed against acetonitrile for 2 days (solution was exchanged 4 times, at least 8 hours in between exchanges). The purified product was stored under argon atmosphere and was stable over 12 months, as was confirmed by ${ }^{1} \mathrm{H}$ NMR. The resulting $\omega$-nosylation (96\%) was determined by integrating the peak from terminal group of PEO at $3.38 \mathrm{ppm}$ and the peak of the methylene group next to the nosylate at $4.32 \mathrm{ppm} .{ }^{1} \mathrm{H} \mathrm{NMR}(500 \mathrm{MHz}$, $\left.\mathrm{CDCl}_{3}, 295 \mathrm{~K}, \delta, \mathrm{ppm}\right): 3.38\left(\mathrm{~s}, 3 \mathrm{H},-\mathrm{OCH}_{2} \mathrm{CH}_{2} \mathrm{O}-\mathrm{CH}_{3}\right), 3.65\left(\mathrm{~m}, 180 \mathrm{H}, \mathrm{OCH}_{2} \mathrm{CH}_{2} \mathrm{O}\right), 4.32(\mathrm{t}, \mathrm{J}=4.6 \mathrm{~Hz}, 2 \mathrm{H}$, $\operatorname{Ar}-\mathrm{O}-\mathrm{CH}_{2}-\mathrm{)}, 8.15\left(\mathrm{~m}, 2 \mathrm{H}, \mathrm{Ar}-\mathrm{NO}_{2}\right), 8.41\left(\mathrm{~m}, 2 \mathrm{H}, \mathrm{Ar}-\mathrm{NO}_{2}\right)$.

\section{Synthesis of PEO- $b$-PEHOx diblock copolymers}

Based on our previous work ${ }^{30}$, PEO- $b$-PEHOx diblock copolymers were synthetized via cationic ringopening polymerization of EHOx in a microwave reactor using PEO-Nos as a macroinitiatior. In a glovebox, a stock solution containing the initiator PEO-Nos, monomer EHOx and chlorobenzene was prepared. The monomer concentration was set to $1 \mathrm{M}$ and a monomer-to-initiator ratio of $30,50,60$, 90 or 140 was used. The desired volume of the solution was transferred into the microwave vials. The vials were sealed in the glovebox under argon atmosphere prior to the transfer into the microwave reactor. 
The polymerization of EHOx was conducted at $140{ }^{\circ} \mathrm{C}$ for various times reaching $100 \%$ monomer conversion depending on the length of the diblock copolymer precursor needed for the triblock copolymer (See synthesis part). The block ratio was determined by integrating the PEO backbone peak at $3.60 \mathrm{ppm}$ and peaks of PEHOx side chain at 1.24 and $0.86 \mathrm{ppm} .{ }^{1} \mathrm{H} \mathrm{NMR}\left(500 \mathrm{MHz}, \mathrm{CDCl}_{3}, 295 \mathrm{~K}, \delta\right.$, ppm): $\left.0.86\left(\mathrm{~m}, 6 \mathrm{H}, \mathrm{CH}_{3}\right), 1.24\left(\mathrm{~m}, 9 \mathrm{H}, \mathrm{CH}\left(\mathrm{CH}_{2} \mathrm{CH}_{3}\right)-\mathrm{CH}_{2} \mathrm{CH}_{2} \mathrm{CH}_{2} \mathrm{CH}_{3}\right)\right), 1.54\left(\mathrm{~m}, 2 \mathrm{H}, \mathrm{N}\left(\mathrm{COCH}_{2} \mathrm{CH}_{2}\right)\right), 2.24$ $\left.\left(\mathrm{m}, 2 \mathrm{H}, \mathrm{N}\left(\mathrm{COCH}_{2} \mathrm{CH}_{2}\right)\right),\right), 3.38\left(\mathrm{~s}, 3 \mathrm{H},-\mathrm{OCH}_{2} \mathrm{CH}_{2} \mathrm{O}-\mathrm{CH}_{3}\right), 3.43\left(\mathrm{~m}, 4 \mathrm{H}, \mathrm{N}\left(\mathrm{COCH}_{2} \mathrm{CH}_{2}\right)-\mathrm{CH}_{2} \mathrm{CH}_{2}\right), 3.65$ (m, $\left.180 \mathrm{H}, \mathrm{OCH}_{2} \mathrm{CH}_{2} \mathrm{O}\right)$.

\section{Synthesis of PEO- $b$-PEHOx- $b$-PEtOz triblock terpolymers}

In a $2 \mathrm{~mL}$ vial, a solution containing PEO-Nos macroinitiator (1 eq., 0,171 g, $0.09 \mathrm{mmol}$ ), chlorobenzene (1.57 $\mathrm{mL}$ ) and EHOx (22 eq., 0,394 g, $2 \mathrm{mmol}$ ) was prepared in the glovebox. The copolymerization was carried out in a microwave at $140^{\circ} \mathrm{C}$ for $40 \mathrm{~min}$. In the glovebox, $0.104 \mathrm{~g}$ of EtOz $(0.5 \mathrm{M}, 1.1 \mathrm{mmol})$ was added to the diblock copolymer mixture. The second copolymerization was carried out again in a microwave at $140{ }^{\circ} \mathrm{C}$. To get the desired EtOz length, the reaction time in the microwave was varied from 1 to $20 \mathrm{~min}$. After the microwave-irradiation, the polymerization mixture was cooled down to room temperature. The mixture was then dissolved in $50 \mathrm{~mL}$ of EtOH. To remove chlorobenzene, homopolymers and residual monomers, the solution was placed into an ultrafiltration reactor (from Millipore Corporation, $5 \mathrm{kDa}$ RC membrane). To achieve a total purification, 5 cycles ( $30 \mathrm{~min}$ ), with 50 $\mathrm{mL}$ of $\mathrm{EtOH}$ and under a pressure of 5 bar, were carried out. To dissolve the polymer, $30 \mathrm{~mL}$ of EtOH was added into the reactor for 10 min without applying any pressure. After removal of the solution, 2 other cycles of 10 min were proceeded. The solvent of the combined solutions was removed under reduced pressure. Products were characterized by ${ }^{1} \mathrm{H}$ NMR. Peaks of PEO- $b$-PEHOx-b-PEtOz spectrum were attributed according to chemical shifts of EHOx and EtOz monomers. Block lengths were calculated using peak integrations with PEO peak at 3.60 ppm as standard (See section 1a in the ESI, Table S1). ${ }^{1} \mathrm{H}$ NMR $\left(500 \mathrm{MHz}, \mathrm{CDCl}_{3}, 295 \mathrm{~K}, \delta, \mathrm{ppm}\right): 0.86\left(\mathrm{~m}, 6 \mathrm{H}, \mathrm{CH}_{3}\right), 1.1\left(\mathrm{~m}, 3 \mathrm{H}, \mathrm{N}\left(\mathrm{COCH}_{2} \mathrm{CH}_{3}\right)-\right.$ $\left.\left.\mathrm{CH}_{2} \mathrm{CH}_{2}\right), 1.24\left(\mathrm{~m}, 9 \mathrm{H}, \mathrm{CH}\left(\mathrm{CH}_{2} \mathrm{CH}_{3}\right)-\mathrm{CH}_{2} \mathrm{CH}_{2} \mathrm{CH}_{2} \mathrm{CH}_{3}\right)\right), 1.54\left(\mathrm{~m}, 2 \mathrm{H}, \mathrm{N}\left(\mathrm{COCH}_{2} \mathrm{CH}_{2}\right)\right), 2.24$ (m, 4H, 
$\left.\mathrm{N}\left(\mathrm{COCH}_{2} \mathrm{CH}_{2}\right)\right), 3.38\left(\mathrm{~s}, 3 \mathrm{H},-\mathrm{OCH}_{2} \mathrm{CH}_{2} \mathrm{O}-\mathrm{CH}_{3}\right), 3.43\left(\mathrm{~m}, 4 \mathrm{H}, \mathrm{N}\left(\mathrm{COCH}_{2} \mathrm{CH}_{2}\right)-\mathrm{CH}_{2} \mathrm{CH}_{2}\right), 3.65(\mathrm{~m}, 180 \mathrm{H}$, $\left.\mathrm{OCH}_{2} \mathrm{CH}_{2} \mathrm{O}\right)$.

Synthesis of PEHOx-b-PEtOz diblock copolymer

Based on our previous work $^{30}$, we added a sequential polymerization step of EtOz to the homopolymerization of EHOx. A microwave vial was prepared containing methyl $p$-toluenesulfonate, EHOx and acetonitrile. The monomer concentration was adjusted to $2 \mathrm{M}$ and a monomer-to-initiator ratio of 60 was used. The microwave vial was then heated to $140{ }^{\circ} \mathrm{C}$ for $30 \mathrm{~min}$ to reach full monomer conversion. In the glovebox, EtOz was then added to the diblock copolymer mixture and its concentration adjusted to $1 \mathrm{M}$. This second copolymerization was then carried out as well at $140{ }^{\circ} \mathrm{C}$ for $12 \mathrm{~min}$. After the microwave-irradiation, the polymerization mixture was cooled down to room temperature. The mixture was then dissolved in $50 \mathrm{~mL}$ of EtOH. To remove chlorobenzene, homopolymers and residual monomers, the solution was placed into an ultrafiltration reactor (from Millipore Corporation, 3.5 kDa RC membrane). To achieve a total purification, 5 cycles (30 min) with $50 \mathrm{~mL}$ of EtOH and under a pressure of 5 bar, were carried out. To dissolve the polymer, $30 \mathrm{~mL}$ of EtOH was added into the reactor for 30 min without applying any pressure. After removal of the solution, 2 other cycles of $30 \mathrm{~min}$ and $30 \mathrm{~mL}$ EtOH were conducted. The solvent of the combined solutions was removed under reduced pressure. ${ }^{1} \mathrm{H}$ NMR $\left(500 \mathrm{MHz}, \mathrm{CDCl}_{3}, 295 \mathrm{~K}, \delta, \mathrm{ppm}\right): 0.86\left(\mathrm{~m}, 6 \mathrm{H}, \mathrm{CH}_{3}\right), 1.1(\mathrm{~m}$, $\left.\left.3 \mathrm{H}, \mathrm{N}\left(\mathrm{COCH}_{2} \mathrm{CH}_{3}\right)-\mathrm{CH}_{2} \mathrm{CH}_{2}\right), 1.24\left(\mathrm{~m}, 9 \mathrm{H}, \mathrm{CH}\left(\mathrm{CH}_{2} \mathrm{CH}_{3}\right)-\mathrm{CH}_{2} \mathrm{CH}_{2} \mathrm{CH}_{2} \mathrm{CH}_{3}\right)\right), 1.54\left(\mathrm{~m}, 2 \mathrm{H}, \mathrm{N}\left(\mathrm{COCH}_{2} \mathrm{CH}_{2}\right)\right), 2.24$ $\left(\mathrm{m}, 4 \mathrm{H}, \mathrm{N}\left(\mathrm{COCH}_{2} \mathrm{CH}_{2}\right)\right), 3.38\left(\mathrm{~s}, 3 \mathrm{H},-\mathrm{OCH}_{2} \mathrm{CH}_{2} \mathrm{O}-\mathrm{CH}_{3}\right), 3.43\left(\mathrm{~m}, 4 \mathrm{H}, \mathrm{N}\left(\mathrm{COCH}_{2} \mathrm{CH}_{2}\right)-\mathrm{CH}_{2} \mathrm{CH}_{2}\right)$. PEHOx 60 -bPEtOz $34 . \theta_{M}=1.22 . M_{n}=15200$ Da. $f=22 \%$.

\section{Self-Assembly}

The self-assembly of PEO- $b$-PEHOx-b-PEtOz triblock terpolymers were done using film rehydration and solvent switch. In all experiments, the final polymer concentration was $0.2 \mathrm{w} / \mathrm{w} \%$. 
Film rehydration: $4 \mathrm{mg}$ of a polymer was dissolved in $200 \mu \mathrm{L}$ of EtOH and placed in a $5 \mathrm{~mL}$ glass roundbottom flask. EtOH was removed by rotary evaporation, and then $2 \mathrm{~mL}$ of Milli-Q water was added. The samples were then stirred at $600 \mathrm{rpm}$ for 7 days at room temperature.

Solvent switch: $4 \mathrm{mg}$ of a polymer was dissolved in $200 \mu \mathrm{L}$ of THF and placed in a $5 \mathrm{~mL}$ glass round bottom flask. $1.8 \mathrm{~mL}$ of Milli-Q water was then added using a syringe pump (AL-1000, WPI, USA) at a rate of $0.01 \mathrm{~mL} \cdot \mathrm{min}^{-1}$ under magnetic stirring $(300 \mathrm{rpm}$ ). To remove THF, the resulting mixture was placed into a regenerated cellulose dialysis membrane (MWCO $1 \mathrm{kDa}$, Spectra Por, USA) and dialyzed against Milli-Q water for 2 days (solvent was exchanged 4 times, at least 8 hours in between exchanges).

Nuclear magnetic resonance spectroscopy (NMR) and 2D- ${ }^{1} \mathrm{H}-\mathrm{NOESY}$ NMR analysis of polymersomes in $\mathrm{D}_{2} \mathrm{O}$

In order to perform NMR measurements in $\mathrm{D}_{2} \mathrm{O}$, polymersomes were prepared by film rehydration. In brief, $4 \mathrm{mg}$ of a polymer was dissolved in $200 \mu \mathrm{L}$ of EtOH and placed in a $5 \mathrm{~mL}$ glass round-bottom flask. EtOH was removed by rotary evaporation, and then $2 \mathrm{~mL}$ of $\mathrm{D}_{2} \mathrm{O}$ was added. The samples were then stirred at $600 \mathrm{rpm}$ for 7 days at room temperature. The resulting polymersomes solution with a concentration of $0.2 \mathrm{w} / \mathrm{w} \%$ was analyzed by $2 \mathrm{D}-{ }^{1} \mathrm{H}-\mathrm{NOESY}$ NMR. On a Bruker Avance III NMR spectrometer $(500.13 \mathrm{MHz})$ at $295 \mathrm{~K}, 2 \mathrm{D}-{ }^{1} \mathrm{H}-\mathrm{NOESY}$ were recorded in $\mathrm{D}_{2} \mathrm{O}$ while ${ }^{1} \mathrm{H}$ NMR spectra were recorded in $\mathrm{CDCl}_{3}$ (0.05\% tetramethylsilane). To buffer any possible acidity, $\mathrm{CDCl}_{3}$ was saturated with $\mathrm{K}_{2} \mathrm{CO}_{3}$. The instrument was equipped with a direct observe 5-mm BBFO smart probe. The experiments were performed at $295 \mathrm{~K}$ and the temperature was calibrated using a methanol standard showing accuracy within $\pm 0.2 \mathrm{~K}$. Spectra were processed with MestReNova software, and chemical shifts were reported in ppm.

\section{Gel Permeation chromatography (GPC)}

GPC traces were analysed and recorded in WinGPC Unichrom software ( $v 8.20$ build 8251, PSS polymer, Germany). Traces of the diblock copolymers or of the reaction mixtures were recorded using 
an Agilent based system composed of a 1200 series pump and autosampler. The GPC system was equipped with a series of linear-S SDV columns (pre-column $(5 \mathrm{~cm})$, three analytical columns $(30 \mathrm{~cm})$ all $5 \mu \mathrm{m}$ particles and $0.8 \mathrm{~cm}$ in diameter, PSS polymer, Germany), followed by a Variable Wavelength Detector (VWD) (1100 series) and a Refractive Index Detector (RI) (1100 series). Detectors and columns were kept at $35{ }^{\circ} \mathrm{C} . \mathrm{CHCl}_{3}$, stabilized with $\mathrm{EtOH}$, was used as the eluent at a flow rate of 1 $\mathrm{mL} \cdot \mathrm{min}^{-1}$. The system was calibrated against narrowly distributed polystyrene (PS) standards.

\section{Transmission electron microscopy (TEM)}

$5 \mathrm{~mL}$ of solution containing self-assembled polymers $(0.2 \mathrm{w} / \mathrm{w} \%$.) was left adsorbing on a formvarcoated and glow discharged 200 mesh copper grid and blotted off after 1 min. A drop of $5 \mu \mathrm{L}$ of water was placed on the grid and blotted off immediately. The action was repeated two times. This procedure was repeated with $5 \mu \mathrm{L}$ of $2 \%$ aqueous uranyl acetate, where the solution was left for $10 \mathrm{~s}$ in the second step insuring sufficient staining of the assemblies. Prepared grids were left drying in air for at least 10 min before imaging them at an acceleration voltage of $80 \mathrm{kV}$ on a Philipps CM100 (Netherlands) transmission electron microscope.

\section{Static and dynamic light scattering (SLS/DLS)}

SLS and DLS experiments were performed on a light scattering spectrometer (LS instruments, Switzerland), equipped with a He-Ne $21 \mathrm{~mW}$ laser $(\lambda=632.8 \mathrm{~nm})$ at scattering angles from $30^{\circ}$ to 150 ${ }^{\circ}$ every $1^{\circ}$ at $25^{\circ} \mathrm{C}$. All samples were diluted 200 times to suppress multiple scattering. $R_{\mathrm{g}}$ was obtained from the SLS data using MIE scattering models (MiePlot, UK). The intensity versus angle curve of samples were fit using Mie scattering models for $\eta=1.35$ and $5 \%$ polydispersity. $R_{\mathrm{g}}$ was then calculated using the obtained $R$ and the formula for a spherical structure: $R_{g}{ }^{2}=(3 / 5) R^{2}$. In the case of DLS, second order cumulant analysis of the data for various angles was performed to obtain the hydrodynamic radius $\left(R_{h}\right)$. 


\section{Cryogenic transmission electron microscopy (Cryo-TEM)}

A $4 \mu \mathrm{L}$ aliquot of a sample was adsorbed onto holey carbon-coated grid (Lacey, Tedpella, USA), blotted off with Whatman 1 filter paper and vitrified into liquid ethane at $-178{ }^{\circ} \mathrm{C}$ using a Leica GP plunger (Leica, Austria). Frozen grids were transferred onto a Talos electron microscope (FEI, USA) using a Gatan 626 cryo-holder. Electron micrographs were recorded at an accelerating voltage of $200 \mathrm{kV}$ and a nominal magnification of $57000 \mathrm{x}$, using a low-dose system $\left(20 \mathrm{e}^{-} / \AA^{2}\right)$ and keeping the sample at low temperature. Micrographs were recorded on a CETA camera. Images were then processed using ImageJ (v 1.51k, NIH, USA) to measure notably micelles sizes and membrane thicknesses.

\section{Bicinchoninic Acid Assay (BCA)}

$100 \mu \mathrm{L}$ of self-assembly solution ( $0.2 \mathrm{w} / \mathrm{w} \%$ ) was incubated with $800 \mu \mathrm{L}$ in a $2.5 \mathrm{~mL}$ vial at $25^{\circ} \mathrm{C}$ (500 rpm). After incubating for 2 hours, the samples were centrifugated at $13000 \mathrm{rpm}$ for $10 \mathrm{~min}$. Then 200 $\mu \mathrm{L}$ of the supernatant was transferred into a 96 -well plate. This was repeated 3 times. The absorbance at $562 \mathrm{~nm}$ was measured using a Spectramax M5 microplate reader (Molecular Devices, USA). The resulting absorbance was the mean value of the triplicates. Each sample was analyzed 10 times for reproducibility. 


\section{Results and discussion}

\section{Synthesis of PEO- $b$-PEHOx-b-PEtOz polymers}

$A B C$ triblocks with a structure of PEO- $b$-PEHOx- $b$-PEtOz represent a novel family of asymmetric triblock terpolymers, which are based on the previously published on PEO- $b$-PEHOx AB diblock copolymers. ${ }^{30}$ The polymers were synthetized via microwave-assisted sequential CROP of EHOx and EtOz on a PEO-Nos macroinitiatior (Figure 1). In order to leverage the power of sequential polymerization for the addition of the monomer $\mathrm{EtO} z$ for the third block $\mathrm{PEtO}$, any remaining traces of EHOx had to be eliminated. EtOz and EHOx have similar reactivities, thus in the presence of EHOx, both monomers would polymerize in those conditions and would then yield a statistical mixture $\mathrm{C}$ of EtOz and EHOx. ${ }^{31}$ The polymerization kinetics of EHOx on PEO-Nos were performed in order to obtain the precise time at which the monomer EHOx is fully consumed to be able to pursue with the addition of EtOz. These polymerization kinetics were performed at $140{ }^{\circ} \mathrm{C}$ in chlorobenzene with $1 \mathrm{M}$ total monomer concentration with PEO-Nos as a macroinitiator. The monomer conversion of EHOx was monitored by ${ }^{1} \mathrm{H}$ NMR and the resulting kinetic plots are depicted in Figure 2 . The linear increase of $\ln \left([\mathrm{M}]_{0} /[\mathrm{M}]_{\mathrm{t}}\right)$ with time demonstrated a constant concentration of propagating species, indicative of a living polymerization of the 2-oxazolines. For monomer-to-initiator ratios of 30, 60, 90 and 140, it was determined that the polymerization needed $30 \mathrm{~min}, 40 \mathrm{~min}, 50 \mathrm{~min}$ and $70 \mathrm{~min}$, respectively, to reach a monomer conversion higher than $98 \%$. Thanks to the use of microwave-assisted polymerization, it was possible to stop the reaction rapidly and precisely. With these optimized conditions, EtOz could now be added directly at a concentration of $0.5 \mathrm{M}$ to the still reactive diblock copolymer precursor PEO-b-PEHOx cleaned of any trace of EHOx monomer. To obtain the desired length of PEtOz, the polymerization was stopped when the necessary conversion was reached and took between $1 \mathrm{~min}$ and 20 min depending on the EtOz length. It was possible to produce a wide variety of $A B C$ triblock terpolymers with this one-pot synthesis in less than 2 hours per batch. By using ultrafiltration for purification, it only took an extra 3 hours to fully purify the crude mixture. All $A B C$ 
triblocks were characterized by ${ }^{1} \mathrm{H}$ NMR and GPC (Figure 3, Table 1). Figure 3 shows representative GPC traces of the macroinitiator $\mathrm{PEO}_{45}-\mathrm{Nos}, \mathrm{PEO}_{45}-b-\mathrm{PEHO}_{65}$ and $\mathrm{PEO}_{45}-b-\mathrm{PEHOx}_{65}-b-\mathrm{PEtO}_{19}$. After addition of PEHOx, the trace of $\mathrm{PEO}_{45}$-Nos was shifted completely to higher molecular weights showing a successful synthesis of $\mathrm{PEO}_{45}-b$-PEHOx 65 with no left-over macroinitiator. Further addition of EtOz resulted in a smaller shift of the trace of $\mathrm{PEO}_{45}-\mathrm{b}-\mathrm{PEHOX}_{65}$ to higher molecular weight showing a successful chain-extension. The smaller shift after adding EtOz could be explained with the logarithmic dependency of retention times and molecular weights. All peaks of the ${ }^{1} \mathrm{H}$ NMR spectrum of PEO- $b$ PEHOx-b-PEtOz (Figure 3) could be assigned to the polymer. The peak at $1.1 \mathrm{ppm}$ could be attributed to the characteristic methyl group of PEtOz, thus proving the successful addition of EtOz. Table 1 comprises the library of synthesized PEO- $b$-PEHOx- $b$-PEtOz with their respective average molecular weight $M_{n}$, dispersity $\Xi_{M}$ and the total hydrophilic weight fraction, $f$, determined by taking both hydrophilic blocks PEO and PEtOz into account (See formula in Table 1).

As the concentration of monomer got lower and the system was more susceptible to side reactions like chain extension, the linear growth of the polymer disappeared for monomer conversion of higher than $90 \%$. This limited the lowest dispersity obtainable with the investigated systems but it still remained satisfactory between 1.3 and 1.4 .
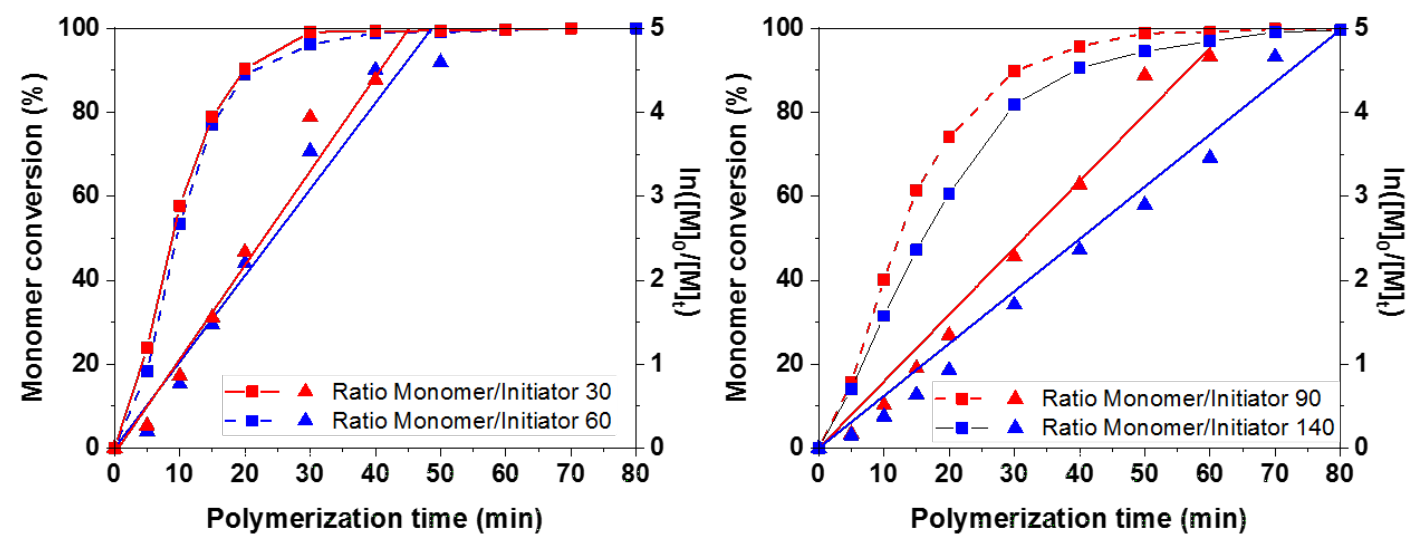

Figure 2 - Microwave-assisted polymerization kinetics of EHOx in chlorobenzene at $140{ }^{\circ} \mathrm{C}$ using various Monomer to Initiator ratios and PEO-Nos as macroinitiator. Left - Ratio monomer to initiator of 30 and 60. Right - Ratio monomer to initiator of 90 and 140. Dashed lines correspond to monomer 
conversion of EHOx (left Y-axis) in \% in function of polymerization time in min. Straight lines correspond to first order kinetic plots (right $Y$-axis) in function of polymerization time in min.

Investigating a broad range of different $f$ was essential to obtain a comprehensive self-assembly phase diagram formed with PEO- $b$-PEHOx- $b$-PEtOz: from the most hydrophilic $\mathrm{PEO}_{45}-b$ - $\mathrm{PEHOx}_{53}-b$-PEtOz $z_{56}(f$ $=42 \%)$ to the most hydrophobic $\mathrm{PEO}_{45}-b-\mathrm{PEHO}_{139}-b-\mathrm{PEtO}_{10}(f=10 \%)$.

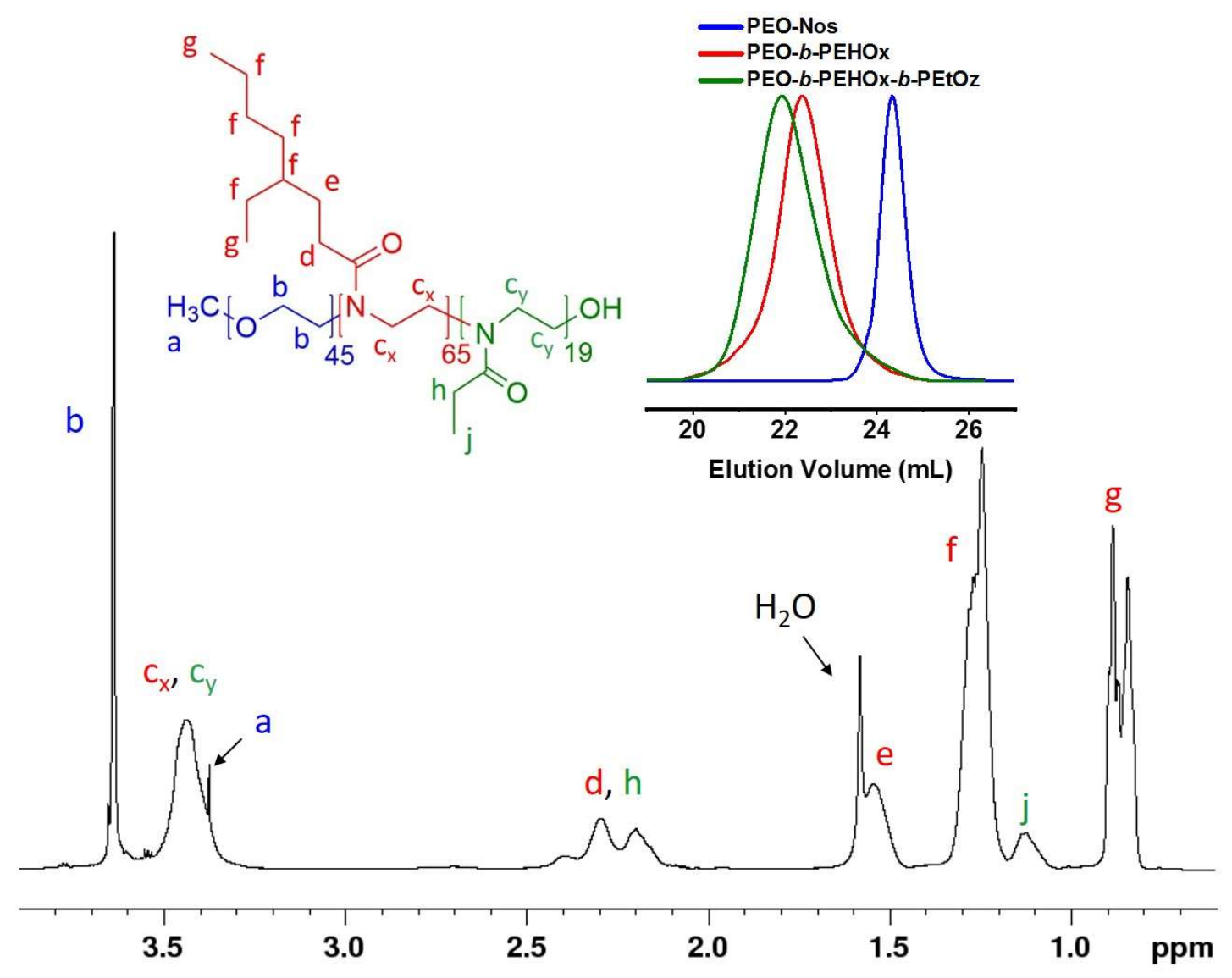

Figure 3 - Representative $\mathrm{NMR}\left({ }^{1} \mathrm{H}, 500 \mathrm{MHz}, C D C l_{3}\right)$ of $\mathrm{PEO}_{45}$-b-PEHOx 65 -b-PEtOz ${ }_{19}$. All peaks have been assigned to the chemical structure of the polymer with a representative $G P C$ trace $\left(\mathrm{CHCl}_{3}\right)$ of the starting macroinitiator PEO $_{45}-N_{O S}$ (blue), the precursor $P^{2} O_{45}-\mathrm{b}-\mathrm{PEHOX}_{65}$ (red) and the resulting triblock PEO $_{45}-b$-PEHOx $65-b$-PEtOz 19 (green). 
Table 1 - Characterization of PEO-b-PEHOx-b-PEtOz triblock terpolymers using ${ }^{1} \mathrm{H} N \mathrm{NR}, \mathrm{GPC}\left(\mathrm{CHCl}_{3}\right)$ and hydrophilic weight fraction, $f .{ }^{a}$ Obtained from ${ }^{1} \mathrm{H}$ NMR. ${ }^{b}$ Obtained by GPC. ${ }^{c}$ Calculated by the equation $f=\left(M_{n}(\right.$ PEO $)+M_{n}($ PEtOz $\left.)\right) /\left(M_{n}(\right.$ PEO $)+M_{n}($ PEHOX $)+M_{n}($ PEtOz $\left.)\right) .{ }^{d}$ Ratio Monomer (EHOX) to Initiator (PEO-Nos). ${ }^{e} S L S$ not possible for non-monodisperse samples (tubes and polymersomes). For calculations of PEHOx and PEtOz block length, see section $1 a$ of the ESI. The remaining triblock terpolymers can be seen in the section $1 b$ of the ESI. For calculations of the length of the polymers segments and their stretching factor, see section 2 of the ESI.

\begin{tabular}{|c|c|c|c|c|c|c|c|c|}
\hline $\begin{array}{c}\mathrm{PEO}_{\mathrm{t}}-b-\mathrm{PEHOx}_{\mathrm{i}}{ }^{-} \\
b-\mathrm{PEtO} \mathrm{z}_{\mathrm{g}}\end{array}$ & $\mathrm{M}_{\mathrm{n}}[\mathrm{Da}]^{\mathrm{a}}$ & $\oplus_{M}^{b}$ & $f[\%]^{c}$ & $\begin{array}{c}\text { Ratio } \\
(\text { Mono/Ini })^{\mathrm{d}}\end{array}$ & $\mathrm{Rh}_{\mathrm{h}}[\mathrm{nm}]$ & $\operatorname{Rg}[n m]^{e}$ & $\rho=\mathrm{R}_{\mathrm{g}} / \mathrm{Rh}_{\mathrm{h}}$ & $\begin{array}{c}\text { Imembrane } \\
\text { vesicles [nm] } \\
\text { (stretching } \\
\text { factor) }\end{array}$ \\
\hline $\mathrm{A}_{45} \mathrm{~B}_{30} \mathrm{C}_{14}$ & 9300 & 1.31 & 36 & 30 & $79 \pm 23$ & - & - & - \\
\hline $\mathrm{A}_{45} \mathrm{~B}_{55} \mathrm{C}_{8}$ & 13600 & 1.33 & 20 & 50 & $109 \pm 14$ & $108 \pm 5$ & 0.99 & - \\
\hline $\mathrm{A}_{45} \mathrm{~B}_{48} \mathrm{C}_{10}$ & 12400 & 1.33 & 23 & 50 & $95 \pm 10$ & $97 \pm 4$ & 1.02 & $\begin{array}{c}6.3 \pm 1.0 \\
(25 \%)\end{array}$ \\
\hline $\mathrm{A}_{45} \mathrm{~B}_{62} \mathrm{C}_{12}$ & 15400 & 1.30 & 21 & 60 & $102 \pm 9$ & $99 \pm 5$ & 0.97 & - \\
\hline $\mathrm{A}_{45} \mathrm{~B}_{55} \mathrm{C}_{13}$ & 14000 & 1.33 & 23 & 60 & $99 \pm 11$ & $101 \pm 5$ & 1.02 & - \\
\hline $\mathrm{A}_{45} \mathrm{~B}_{48} \mathrm{C}_{14}$ & 12900 & 1.32 & 26 & 50 & $105 \pm 16$ & $105 \pm 4$ & 1.00 & - \\
\hline $\mathrm{A}_{45} \mathrm{~B}_{49} \mathrm{C}_{17}$ & 12800 & 1.37 & 28 & 50 & $112 \pm 11$ & $108 \pm 6$ & 0.96 & - \\
\hline $\mathrm{A}_{45} \mathrm{~B}_{65} \mathrm{C}_{19}$ & 16700 & 1.36 & 23 & 60 & $111 \pm 13$ & $108 \pm 7$ & 0.97 & $7.8 \pm 0.8$ \\
\hline $\mathrm{A}_{45} \mathrm{~B}_{54} \mathrm{C}_{24}$ & 14900 & 1.39 & 29 & 50 & $106 \pm 11$ & $109 \pm 6$ & 1.03 & - \\
\hline $\mathrm{A}_{45} \mathrm{~B}_{56} \mathrm{C}_{32}$ & 16200 & 1.41 & 32 & 60 & $98 \pm 8$ & $96 \pm 5$ & 0.98 & - \\
\hline $\mathrm{A}_{45} \mathrm{~B}_{62} \mathrm{C}_{35}$ & 17700 & 1.37 & 31 & 60 & $104 \pm 14$ & $102 \pm 4$ & 0.98 & $\begin{array}{c}8.2 \pm 1.0 \\
(23 \%)\end{array}$ \\
\hline $\mathrm{A}_{45} \mathrm{~B}_{53} \mathrm{C}_{56}$ & 18000 & 1.38 & 42 & 50 & $21 \pm 7$ & - & - & - \\
\hline $\mathrm{A}_{45} \mathrm{~B}_{87} \mathrm{C}_{10}$ & 20100 & 1.39 & 15 & 90 & $108 \pm 19$ & $103 \pm 6$ & 0.95 & $\begin{array}{c}9.9 \pm 0.9 \\
(22 \%)\end{array}$ \\
\hline $\mathrm{A}_{45} \mathrm{~B}_{96} \mathrm{C}_{11}$ & 22000 & 1.39 & 14 & 90 & $114 \pm 28$ & $106 \pm 7$ & 0.93 & - \\
\hline $\mathrm{A}_{45} \mathrm{~B}_{138} \mathrm{C}_{14}$ & 30500 & 1.47 & 11 & 140 & $476 \pm 175$ & $-{ }^{e}$ & $-e$ & - \\
\hline $\mathrm{A}_{45} \mathrm{~B}_{139} \mathrm{C}_{10}$ & 30300 & 1.45 & 10 & 140 & $568 \pm 156$ & $-\mathrm{e}$ & $-\mathrm{e}$ & $\begin{array}{c}12.9 \pm 1.5 \\
(18 \%)\end{array}$ \\
\hline
\end{tabular}




\section{Self-Assembly of PEO- $b-\mathrm{PEHOx}-b-\mathrm{PEtO} z$}

The self-assembly of PEO- $b$-PEHOx- $b$-PEtOz polymers in aqueous solution was studied using two different techniques: film rehydration and solvent switch. The final concentration of the selfassembled polymer was always set to $0.2 \mathrm{w} / \mathrm{w} \%$. For film rehydration, the polymer solutions were stirred extensively for one week as a stirring time of only one day only resulted mostly in a precipitated polymer. For solvent switch, the self-assemblies were completely formed at the end of the dialysis step after 2 days. Further stirring did not yield any change in the self-assemblies. ${ }^{30}$ All self-assemblies were analysed via TEM and DLS and polymersomes were further characterized by SLS and Cryo-TEM (Figure 4 and Table 1).

\section{Solvent Switch}

Using solvent switch, monodisperse micelles $\left(R_{h}=13 \pm 1 \mathrm{~nm}\right.$, see figure S1 in the ESI) were obtained for all triblock terpolymers but $A_{45} B_{87} C_{10}, A_{45} B_{96} C_{11}, A_{45} B_{138} C_{10}$ and $A_{45} B_{139} C_{10}$. Micelles from $A B C$ triblocks consist of U-shaped polymers, since both blocks $\mathrm{A}$ and $\mathrm{C}$ will be in contact with the solvent. This would lead to large degree of entanglements between the B blocks, which was the suspected explanation why solvent switch lead kinetically trapped micelles. With hydrophilic weight fractions, $f$, between $10 \%$ and $15 \%$, they could not self-assemble with this method, forming only aggregates and polymer film as observed by TEM (See figure S2 in the ESI). The study was then focused on the film rehydration technique as it yielded more diverse and interesting structures, most notably polymersomes.

\section{Film rehydration}

Micelles and worms. The self-assembly of $\mathrm{A}_{45} \mathrm{~B}_{53} \mathrm{C}_{56}(f=42 \%)$ also led to the formation of micelles (Figure $4 . \mathrm{E}, \mathrm{R}_{\mathrm{h}}=21 \pm 7 \mathrm{~nm}$ ) when film rehydration was used. Those micelles exhibited a higher dispersity in size than the one formed by solvent switch $\left(R_{h}=11 \pm 1 \mathrm{~nm}\right)$. This is in accordance with the differences highlighted in our previous work between film rehydration and solvent switch. ${ }^{30}$ Film rehydration is a top-down approach which leads to kinetically stable structures while solvent switch, 
a bottom-up approach which yielded thermodynamically favoured structures. The terpolymer $\mathrm{A}_{45} \mathrm{~B}_{30} \mathrm{C}_{14}(f=36 \%)$ self-assembled into worms, which are elongated micelles, as revealed by TEM (Figure 4.D). This explained the surprisingly high $R_{h}$ determined by DLS which also indicated a high polydispersity in sizes $\left(R_{h}=79 \pm 23\right)$. Indeed, the hydrodynamic radius measurements are based on spherical models and are not adapted to complex cylinder-like shapes. This led to a discrepancy to the dimension observed in several TEM images, revealing an average worm thickness of $13.9 \pm 1.8 \mathrm{~nm}$ and typical worm's lengths between 50 and $400 \mathrm{~nm}$.

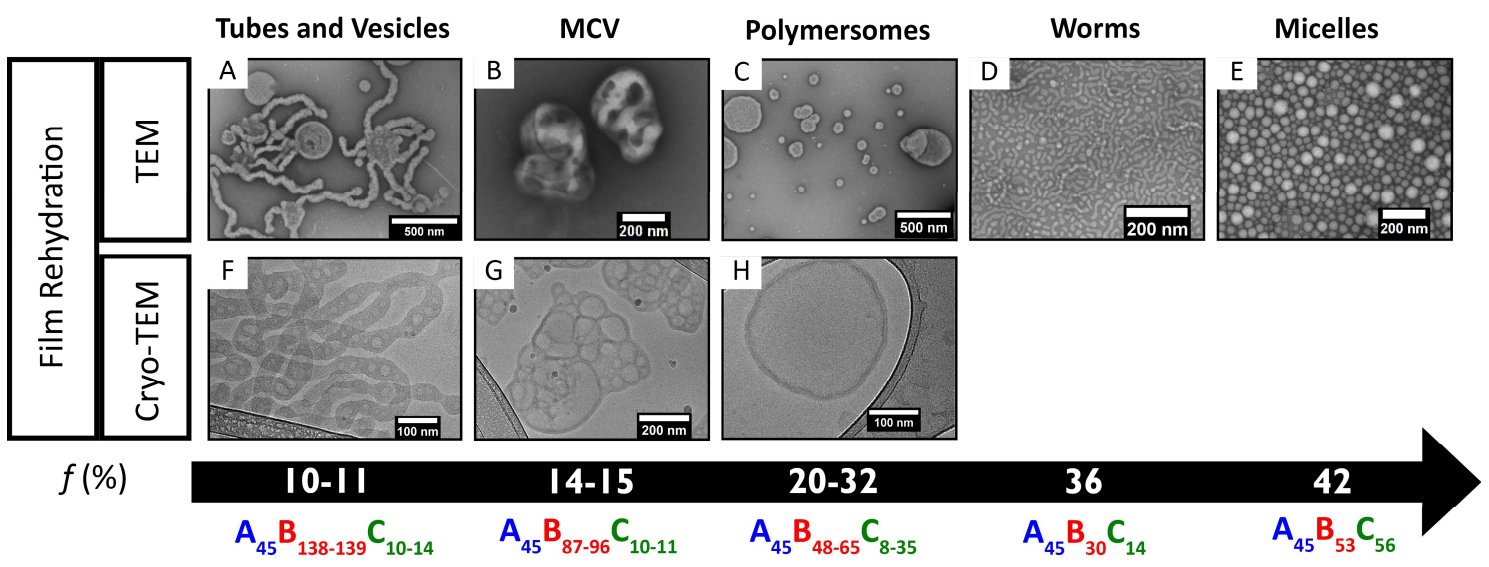

Figure 4-TEM (A-E) and Cryo-TEM (F-H) images of the self-assemblies formed by film rehydration of $A B C$ triblock terpolymers PEO-b-PEHOx-b-PEtOz for increasing hydrophilic weight fraction $f$. MCV= Multicompartment Vesicles. Supplementary and in higher resolution Cryo-TEM images can be seen for polymersomes in figure S3, for MCV in figure S4 and tubes and vesicles in figure S5 in the ESI.

Polymersomes. Nanoscopic polymersomes were formed using self-assembly by film rehydration with a wide range of $A B C$ triblock terpolymers, $A_{45} B_{48-65} C_{8-35}(f=20-32 \%)$. Comparison to literature data showed that these values for $f$ and the formation of polymersomes were characteristic for the polymer system investigated. ${ }^{15}$ The vesicles were formed in homogenous phases but showed a large dispersity in sizes. DLS measurements revealed $R_{h}$ values between 200 and $400 \mathrm{~nm}$. In order to narrow down the size distribution and obtain a reliable characterization by SLS, the samples were extruded through a $200 \mathrm{~nm}$ membrane. By combining data from SLS with data from DLS, it was possible to confirm the suspected morphology of self-assembled structures, i.e polymersomes. As an example, self- 
assemblies from $A_{45} B_{49} C_{17}$, exhibited an $R_{h}$ after extrusion of $112 \pm 11 \mathrm{~nm}$. Following a SLS experiment exploiting the MIE model, a radius of gyration $\left(R_{g}\right)$ of $108 \pm 6 \mathrm{~nm}$ was calculated (See figure $\mathrm{S} 6$ in the ESI). When dividing $R_{\mathrm{g}}$ by $\mathrm{R}_{\mathrm{h}}$, the form factor $\rho$ was obtained. This structure property reflected the radial density distribution of a particle. The typical value for hollow spheres with an infinitely thin membrane, i.e. polymersomes, is 1.0. ${ }^{32-33}$ For $\mathrm{A}_{45} \mathrm{~B}_{49} \mathrm{C}_{17}$, a resulting $\rho$ of 0.97 indicated the formation of polymersomes. For the other ABC triblocks, similar results were obtained as $\rho$ values oscillated around 1.0, from 0.96 for $A_{45} B_{49} C_{17}$ to 1.03 for $A_{45} B_{54} C_{24}$. The presence of polymersomes was further confirmed by TEM as the typical topology for vesicles in TEM was found (Figure 4.C, see figure S7 in the ESI for higher resolution). Under the vacuum of TEM, this kind of soft and hollow self-assembly is flattened and folds onto itself displaying a characteristic wrinkled structure. ${ }^{34}$ On top of that, a white halo was observable at the edge of the structures and suggested the presence of a membrane (See figure $\mathrm{S} 8$ in the ESI). Due to the negative staining, it was not possible to determine the membrane thickness. To measure the membrane thickness, visualize the polymersomes in their native environment and ultimately prove their formation, Cryo-TEM was conducted on self-assemblies of selected $A B C$ triblocks, namely $A_{45} B_{48} C_{10}, A_{45} B_{65} C_{19}$ and $A_{45} B_{62} C_{35}$ (Figure $4 . H$, see figure $S 7$ for higher resolution and figure $\mathrm{S} 3$ for supplementary Cryo-TEM images in the ESI). $A_{45} B_{48} C_{10}$ and $A_{45} B_{65} C_{19}$ were chosen to compare the membrane thicknesses of their resulting polymersomes, 48 units of PEHOx being the shortest PEHOx block forming polymersomes and 65 units of PEHOx being the longest. $\mathrm{A}_{45} \mathrm{~B}_{62} \mathrm{C}_{35}$ was chosen as it has the longest PEtOz block while having a comparable PEHOx length to $\mathrm{A}_{45} \mathrm{~B}_{65} \mathrm{C}_{19}$. Cryo-TEM confirmed hollow spheres (polymersomes) from all of these $A B C$ triblocks. Using several Cryo-TEM images, the membrane thicknesses were determined, $\mathrm{A}_{45} \mathrm{~B}_{48} \mathrm{C}_{10}-I_{\text {membrane }}=6.3 \pm 1.0$ $\mathrm{nm}, \mathrm{A}_{45} \mathrm{~B}_{65} \mathrm{C}_{19}-\mathrm{I}_{\text {membrane }}=7.8 \pm 0.8$. It suggested a dependency between the block of length of the hydrophobic block, EHOx, and the membrane thickness. $\mathrm{A}_{45} \mathrm{~B}_{62} \mathrm{C}_{35}$ had a membrane thickness of $8.2 \pm$ 1.0, which was comparable to the membrane thickness of $A_{45} B_{65} C_{19}$ and showed that a longer block of PEtOz neither significantly influenced the thickness of the membrane nor prevented the formation of polymersomes. Due to the values on membrane thickness from Cryo-TEM, these values could not be 
put in perspective to the hydrophobic polymer PEHOx segments of the polymer chains. Comparing the theoretical length of PEHOx as a random coil and in a stretched conformation, both polymersomes had a mixed conformation due to the branched side chain of PEHOx. The polymers were stretched by a similar percentage ( $25 \%$ for $\mathrm{A}_{45} \mathrm{~B}_{48} \mathrm{C}_{10}$ and $23 \%$ for $\mathrm{A}_{45} \mathrm{~B}_{65} \mathrm{C}_{19}$, see ESI for details) in both instances. This is also reflected by the small difference membrane thickness measured by Cryo-TEM. Hence, the hydrophobic polymer PEHOx showed a similar overall conformation on both ends of polymersomeforming triblocks and by extension in all the studied polymersomes. The lower amount of stretching for the longer polymer was noted but could easily be due to statistical deviations.

Multicompartment Vesicles. The self-assembly of $\mathrm{A}_{45} \mathrm{~B}_{87} \mathrm{C}_{10}$ and $\mathrm{A}_{45} \mathrm{~B}_{96} \mathrm{C}_{11}$ formed multicompartment vesicles (MCV). With DLS and SLS measurements indicating that those self-assemblies were hollow spheres $\left(R_{h}=108 \pm 19, \rho=0.95, R_{h}=114 \pm 28, \rho=0.93\right.$, respectively), those structures were at initially presumed to be regular polymersomes. But the TEM images revealed a more complex structure (Figure 4.B, see figure S9 for higher resolution in the ESI). Besides being non-spherical, compared to the characteristic morphology of polymersomes, the images showed more irregular contrast and wrinkles which hinted at the presence of more than one hollow cavity as it was previously observed for PEO- $b$-PEHOx forming pseudo-vesicles structures. ${ }^{30}$ Cryo-TEM images unveiled these structures to be multicompartment vesicles (Figure 4.G, see figure S9 for higher resolution and figure S4 for supplementary Cryo-TEM images in the ESI). A regular membrane of constant thickness $\left(I_{\text {membrane }}=9.9\right.$ \pm 0.9 for $\left.\mathrm{A}_{45} \mathrm{~B}_{87} \mathrm{C}_{10}\right)$ in between numerous cavities could be observed. Following the same calculations as for the polymersomes, the PEHOx in the self-assembled $\mathrm{A}_{45} \mathrm{~B}_{87} \mathrm{C}_{10}$, showed a conformation which was $22 \%$ stretched. Similar to the polymersomes, the yet longer PEHOx segments leaned more towards the random coil and were less stretched, and again yielded a small increase in membrane thickness. However, the differences were still too small to act as proof and only hinted a possible tendency. 
Polymersomes and Tubes. $\mathrm{A}_{45} \mathrm{~B}_{138} \mathrm{C}_{14}$ and $\mathrm{A}_{45} \mathrm{~B}_{139} \mathrm{C}_{10}$ were the only triblock terpolymers to not form pure phases by self-assembly. Both of them formed polymersomes and tubes, which are elongated polymersomes. TEM images confirmed both by showing the presence of typical structures resembling tubes and polymersomes (Figure 4.A, see figure S10 for higher resolution in the ESI). The tubes showed a typical length being between 1000 and $3000 \mathrm{~nm}$. Polymersomes of these $A B C$ triblocks showed a white halo on the edge, which was the same difference of contrast as previously observed for shorter $A B C$ triblocks like $A_{45} B_{65} C_{19}$. However, it appeared to be significantly bigger for the longer $A B C$ triblocks which already suggested polymersomes with thicker membranes (See figure S8 in the ESI). Due to the presence of two distinct populations, polymersomes and tubes, and the subsequent inhomogeneity, only DLS and not SLS was conducted $\left(A_{45} B_{138} C_{14}, R_{h}=476 \pm 175 \mathrm{~nm}\right.$ and $\left.A_{45} B_{139} C_{10}, R_{h}=568 \pm 156 \mathrm{~nm}\right)$. The large polydispersity in sizes prohibited the use of SLS on these samples. With Cryo-TEM, the formation of the polymersomes with a thicker membrane $\left(I_{\text {membrane }}=12.9 \pm 1.5\right)$ was proven. Similar to above, this allowed for a calculation on the conformation of the PEHOx segments with the polymersome membranes. The polymers were $18 \%$ stretched for $A_{45} B_{139} C_{10}$, which finally confirmed the suggested trend that longer PEHOx chains were more densely packed than shorter ones. CryoTEM also allowed for a visualisation of the inner structure of the tubes. Their width vary (Overall thickness $=43 \pm 12 \mathrm{~nm}$ ) and they were all filled with a myriad of spherical hollow cavities which are homogenous in sizes $(R=12.6 \pm 2.2 \mathrm{~nm})$. This is very much in between the stretched conformations of PEO-45 (16.0 nm, 74\% stretched at $12.6 \mathrm{~nm})$ and PEtOz $(3.5 \mathrm{~nm})$, suggesting that these cavities were filled with hydrated and mostly stretched hydrophilic polymer segments of both kinds.

All results for film rehydration were summarized in a self-assembly phase diagram (Figure 5). The diagram emphasizes the wide range of self-assembled structures which were possible with this $A B C$ triblock and could only be proven using a combination of DLS, SLS, TEM and Cryo-TEM as complimentary analytical methods. Furthermore, solvent switch produced micelles which are much more monodisperse in terms of size compared to ones from film rehydration. Solvent switch allowed for targeting an additional self-assembly structure with the same terpolymer, for example for $A_{45} B_{65} C_{19}$ 
which resulted either in micelles (solvent switch) or in polymersomes (film rehydration). This showed the importance of using various self-assembly techniques to unlock more potential applications of amphiphilic block copolymers. As previously shown ${ }^{30}$, the branched side chain of PEHOx allowed for unique and distinct structures like the multicompartment vesicles reported in here. They confirmed the intriguing influence of the side chain of PEHOx to form such complex self-assemblies.

Among the obtained self-assembled structures formed, polymersomes were of interest due to the ability of their membrane to confine aqueous media. $A B C$ polymersomes were especially intriguing because their membrane can be asymmetric and therefore can mimic the natural orentiation of cell membrane ${ }^{17,19,21}$. To probe the asymmetry in the case of PEO- $b$-PEHOx- $b$-PEtOz polymersomes, this study focused on $\mathrm{A}_{45} \mathrm{~B}_{48-65} \mathrm{C}_{8-35}$, as they produced pure phases of polymersomes and the dependence of the asymmetry on PEtOz block length could be studied in detail. 


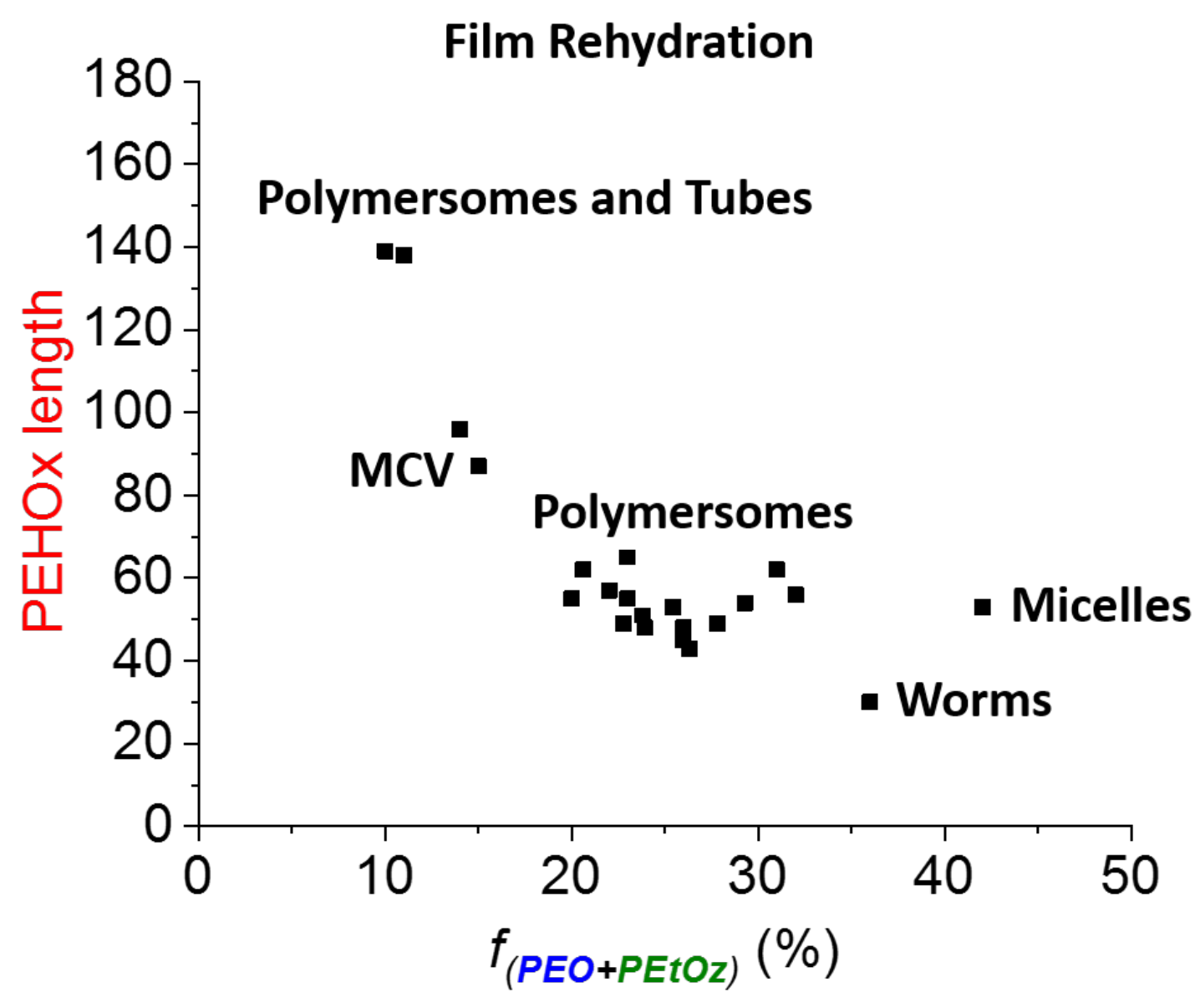

Figure 5 - Self-Assembly Phase diagram of PEO-b-PEHOx-b-PEtOz using film rehydration. MCV=Multicompartment Vesicles.

Orientation of PEO- $b$-PEHOx- $b$-PEtOz chains in the membrane of polymersomes

Polymersomes formed by $A B C$ triblocks with two different hydrophilic blocks $(A, C)$ can result in polymersomes with 3 different scenarios with respect to the orientation of their hydrophilic blocks: either $A$ is outside, $C$ is outside or there is a mix of $A$ and $C$ on the inside and outside (Figure 1 ). One way to have a preferred orientation and create an asymmetric membrane, is to tailor the length of the $A$ and $C$ blocks. This approach proved to be successful for the ABC triblocks PEO- $b$-PDMS- $b$ $\mathrm{PMOXA}^{20}$ and PEO- $b-\mathrm{PCL}-b-\mathrm{PMOXA}{ }^{17}$ where the orientation could even be flipped by modifying one block with a large molecule. ${ }^{18}$ 
To show the presence of a longer PEtOz block on the surface of PEO-b-PEHOx-b-PEtOz polymersomes, the composition on the surface was tested using a difference in the chemical composition of PEO and PEtOz. Bicinchoninic acid assay (BCA), an assay to measure peptide concentration, was used to detect only PEtOz since polyoxazolines as quasi-polypeptides, contain amide bonds while the polyether PEO does not. This assay is based on the reduction of $\mathrm{Cu}^{2+}$ to $\mathrm{Cu}^{+}$by a peptide bond in alkaline medium and its further complexation with bicinchoninic acid yielding a purple complex with a maximum absorbance at $562 \mathrm{~nm}$. All results for each category of polymers are summed up in figure 6 . $\mathrm{PEO}_{45}(2 \mathrm{kDa})$ yielded a small base signal $(0.105 \pm 0.003)$ due to the lack of peptide-like bonds and the results were coherent with Konishcheva et al. ${ }^{17} \mathrm{AB}$ diblock copolymers $\mathrm{PEO}_{45}-b-\mathrm{PEHOX}_{40}, \mathrm{PEO}_{45}-b$ $\mathrm{PEHOx}_{46}, \mathrm{PEO}_{45}-b-\mathrm{PEHO}_{57}$ and $\mathrm{PEO}_{45}-b-\mathrm{PEHO}_{62}$ were selected to have similar repeating units of EHOx to the $A B C$ triblock forming polymersomes. $A B$ diblock copolymer yielded a signal higher than $\mathrm{PEO}_{45}$ $(0.163 \pm 0.009)$ due to a small reactivity of PEHOx. Despite being hydrophobic PEHOx was still able to react mildly to the BCA assay as the PEHOx block is not completely covered. This control signal of a pure PEO outer leaflet was similar to all polymersomes from $A B C$ triblocks with a block length of $C$ (EtOz) inferior to 32 units $(0.167 \pm 0.010)$. These comparable signals $(0.163 \pm 0.009$ and $0.167 \pm$ 0.010), were a strong indicator that polymersomes formed from these $A B C$ triblocks had an outer leaflet purely of PEO and no PEtOz. This was further confirmed by a sharp increase in absorbance for all triblocks with $C(E t O z)$ superior or equal to 32 units $(0.458 \pm 0.072)$. This sharp increase for selfassemblies from $A B C$ triblocks like $A_{45} B_{56} C_{32}$ indicated that the orientation transitioned from asymmetric ( $\mathrm{A}$ outside and $\mathrm{C}$ inside) to either a mixed phase between $\mathrm{A}$ and $\mathrm{C}$ or a reverse asymmetric orientation with purely $\mathrm{C}$ on the outer leaflet. In an effort to shed more light on this orientation, a $\mathrm{BC}$ diblock copolymer, $\mathrm{PEHOx}_{60}-b-\mathrm{PEtO}_{34}$, was synthetized to compare with a control signal of a pure EtOz outer leaflet for similar repeating units of EHOx. This BC diblock copolymer yielded a signal significantly higher $(0.935 \pm 0.107)$. Both polymersomes from $A B C$ triblocks with $C(E t O z)$ superior or equal to 32 units can be estimated to be about $40 \%$. Taking the signal from $\mathrm{PEHOx}_{60}-b-\mathrm{PEtO}_{34}$ as the reference when $100 \%$ of PEtOz is outside and the signal $A B$ diblock copolymers as the reference when 
$0 \%$ of PEtOz is outside, the percentage of PEtOz outside could be calculated and was rounded to the next $5 \%$ to respect measurement errors.

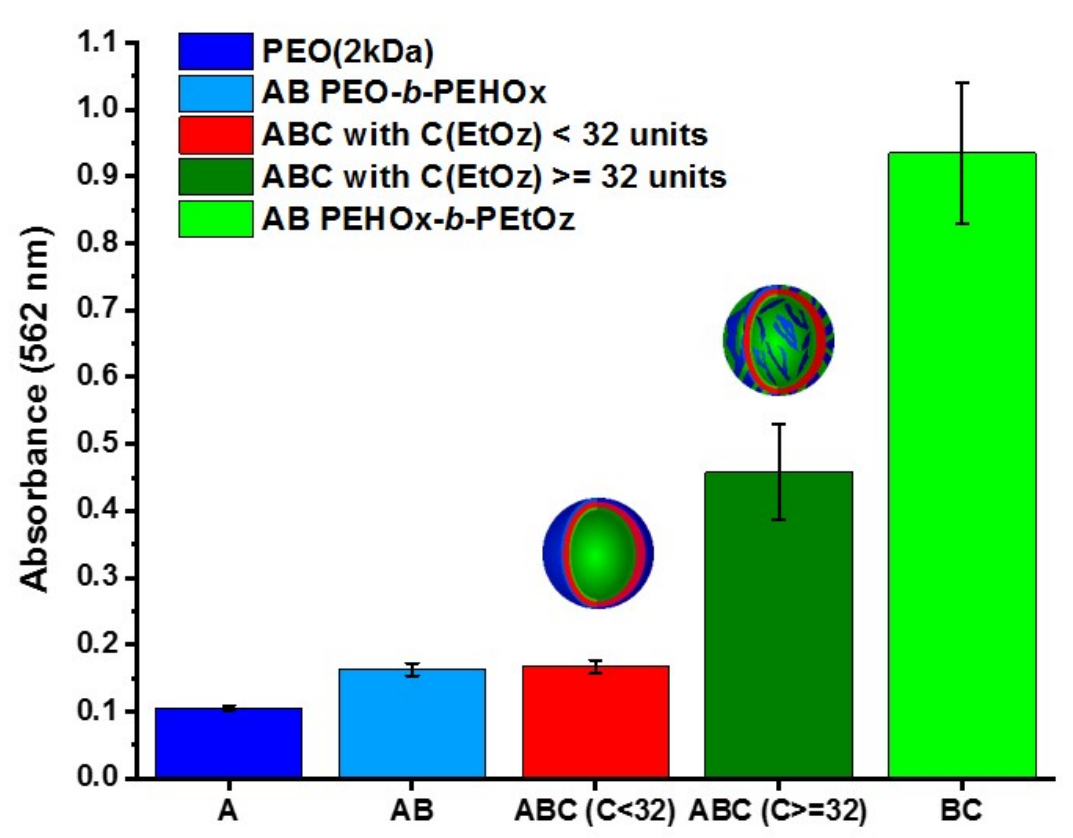

Figure 6 - Absorbance (562 nm) of the supernatant after conducting BCA assay on $P E O(2 \mathrm{kDA})(A$ block only), PEO-b-PEHOx (AB diblock copolymers) and PEO-b-PEHOx-b-PEtOz (ABC triblocks). The graphs represent mean values measured over various samples. For $A B: A_{45} B_{40-62}$. For $A B C(C<32)$ : $A_{45} B_{48-65} C_{8-24}$. For $A B C(C \geq 32): A_{45} B_{56-62} C_{32-35}$. For $B C: B_{60} C_{34}$.

In addition to the approach discussed above, ${ }^{1} \mathrm{H}$ NMR and $2 \mathrm{D}-{ }^{1} \mathrm{H}-\mathrm{NOESY}-\mathrm{NMR}$ was used to determine the 3D spatial correlations and hydrogen bonding interactions between the two hydrophilic blocks $\mathrm{A}$ and $C$ in polymersomes. ${ }^{35-36}$ NMR spectra were recorded in $\mathrm{D}_{2} \mathrm{O}$ of polymersomes from a representative $A B C$ triblock with $C(E t O z)$ inferior to 32 units in length, $A_{45} B_{54} C_{24}$, and with $C(E t O z)$ equal or superior to 32 units in length, $A_{45} B_{56} C_{32}$ (Figure 7). The peaks of interest in the ${ }^{1} \mathrm{H}$ NMR spectra were the ones at $3.60 \mathrm{ppm}$ of the backbone of PEO ( $\mathrm{b}$ in figure 7, $3.60 \mathrm{ppm}$ ) and the overlapping peaks at $0.96 \mathrm{ppm}$ of the methyl group of the side chain of PEtOz ( $\mathrm{j}$ in figure $7,0.96 \mathrm{ppm}$ ) and the protons of the side chain of PEHOx ( $f$ in figure 7, $0.96 \mathrm{ppm}$ ). Comparing the intensity of both peaks (See figure 
S11 in the ESI), the ratio for $A_{45} B_{54} C_{24}\left(I_{\text {PEO }} / I_{\text {PEHOX }+ \text { PEtOz }}=13\right)$ was significantly higher than for $A_{45} B_{56} C_{32}$ $\left(I_{\text {PEO }} / I_{\text {PEHOX }+ \text { PEtOz }}=1.86\right)$. It suggested that PEO was located at the outside of the polymersomes in the case of $A_{45} B_{54} C_{24}$ while both PEHOx and PEtOz were shielded, which was very much in line with the results from the $B C A$ assay. As for $A_{45} B_{56} C_{32}$, it hinted a mixture of PEO and PEtOz on the outer leaflet of the polymersome membrane. Considering that the polymer had similar amount of PEHOx and PEO but an increased amount of PEtOz, the difference observed in the NMR spectra could be associated with PEtOz and not PEHOx although it contributed to the signal at $0.96 \mathrm{ppm}$. PEtOz was thus not shielded anymore, suggesting it was now also located outer leaflet of the polymersome membrane. Since the PEO signal was still present, a mixed surface of both polymers could be assumed. The 2D${ }^{1} \mathrm{H}$-NOESY NMR confirmed this assumption as it showed cross signals between the methylene protons of the side chain of PEtOz ( $\mathrm{j}$ in figure 7, $0.96 \mathrm{ppm}$ ) and the backbone of PEO ( $\mathrm{b}$ in figure 7, $3.60 \mathrm{ppm}$ ) for $A_{45} B_{56} C_{32}$ but not for $A_{45} B_{54} C_{24}$. This proved that PEO and PEtOz were able to interact with each other for $\mathrm{A}_{45} \mathrm{~B}_{56} \mathrm{C}_{32}$. Further cross signals between the methyl protons of the side chain of PEtOz ( $\mathrm{j}$ in figure 7, $0.96 \mathrm{ppm}$ ), the protons of the backbone of PEtOz ( $c_{y}$ in figure 7, $3.43 \mathrm{ppm}$ ) and the methylene protons of the side chain of PEtOz ( $h$ in figure 7, $2.24 \mathrm{ppm}$ ) were again exclusive to $A_{45} B_{56} C_{32}$. This was the final confirmation that both, PEtOz and PEO, were located on the outer leaflet of the membrane in the case of $\mathrm{A}_{45} \mathrm{~B}_{56} \mathrm{C}_{32}$ forming a mixed surface with about $40 \%$ of PEtOz estimated outside. For $\mathrm{A}_{45} \mathrm{~B}_{54} \mathrm{C}_{24}$, however, PEtOz was located inside and remained shielded while PEO was located outside thus forming an asymmetric polymersome.

These results were even more striking as they overlap with previous research on asymmetric polymersomes from PEO- $b$-PCL- $b$-PMOXA. Polymersomes from that ABC triblock also showed either a pure PEO phase on the outer leaflet on the membrane, or a mixed one with PEO and PMOXA. A pure PMOXA surface was not observed when screening several unmodified PEO- $b$-PCL- $b$-PMOXA ABC triblocks. ${ }^{17-18}$ 


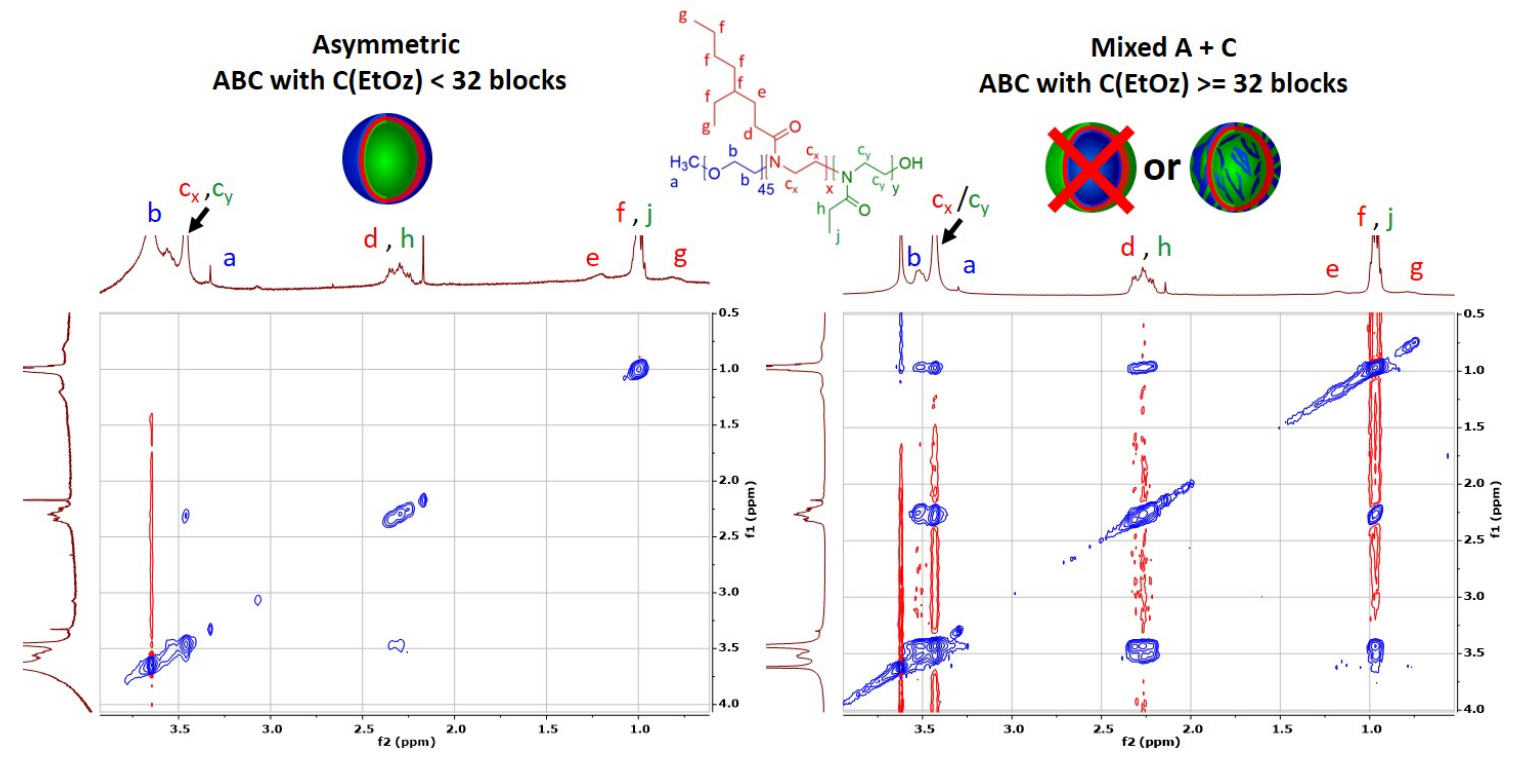

Figure 7 - Representative $2 D-{ }^{1} \mathrm{H}$-NOESY NMR in $\mathrm{D}_{2} \mathrm{O}$ of (left) asymmetric polymersomes from $A B C$ triblock terpolymers $P E O-\mathrm{b}-\mathrm{PEHOx}-\mathrm{b}-\mathrm{PEtO} z$ with EtOz length less than 32 blocks, here $\mathrm{PEO}_{45} \mathrm{-b}-$ $P E H O x_{54}-\mathrm{b}-P E t O z_{24}$ and (right) mixed $A$ and $C$ polymersomes from $A B C$ triblock terpolymers $P E O-b-$ $P E H O x-b-P E t O z$ with EtOz length equal or superior to 32 units of PEtOz, here $P^{2} O_{45}-\mathrm{b}-P_{E H O x_{56}-\mathrm{b}-}$ $\mathrm{PEtO}_{32}$.

\section{Conclusions}

A library of novel amphiphilic asymmetric PEO- $b$-PEHOx- $b$-PEtOz ABC triblock terpolymers with different PEHOx and PEtOz block lengths was obtained via a one-pot synthesis. The sequential polymerisation started from a PEO-Nos macroinitiator where EHOx and EtOz were added one after the other. The synthesis was well-controlled, producing a large array of $A B C$ triblocks with 45 units of PEO, PEHOx up to 139 units and PEtOz with up to 56 units in less than 2 hours. Self-assembly by solvent switch predominantly led to the formation of monodisperse micelles. Using film rehydration, the formed nanostructures followed the established self-assembly theory. With decreasing hydrophilic weight fraction $f$, the self-assembly structures started from micelles, followed by worms as elongated micelles then polymersomes and then multicompartment vesicles (MCV). Finally, tubes as elongated vesicles finished this textbook series of self-assembly structures. However, no pure phases of tubes were formed, but also polymersomes with notably thicker membrane. All those structures were analysed in-depth using dynamic and static light scattering, TEM and Cryo-TEM. MCVs formed by PEO- 
$b$-PEHOx- $b$-PEtOz echoed to its diblock precursor PEO-b-PEHOx which could also form complex structures like multicompartment micelles and yolk/shell nanoparticles. This confirmed the potential of PEHOx in self-assembly to obtain complex nanoparticles from a single material as it is a hydrophobic block with a long branched side chain. Comparing the measured membrane thickness with the theoretical length of the PEHOx segments, it became evident that PEHOx was predominantly in a random coil state and only partially stretched to the special requirements of the side chain. With growing chain length, this stretching decreased from $25 \%$ for 48 repeating units to $18 \%$ for 138 units. Nanoscale polymersomes assembled from $\mathrm{PEO}_{45}-b-\mathrm{PEHOx}_{48-65}-b-\mathrm{PEtO}_{\mathrm{x}}$ exhibited an asymmetric orientation of the membrane for a PEtOz length lower than 32 units as proven by two independent methods, namely BCA assay and $2 \mathrm{D}-{ }^{1} \mathrm{H}-\mathrm{NOESY}$ NMR. The same methods proved that a mixed phase of PEO and PEtOz was located outside of the polymersomes for PEtOz longer or equal to 32 units. Coupled with the peptide-like nature of the membrane formed with PEHOx as an oxazoline, this preferred orientation opens new opportunities toward directed insertion of transmembrane proteins into asymmetric polymersomes.

\section{Acknowledgments}

The authors acknowledge the financial support from the Swiss National Science Foundation (SNSF) especially in light of the National Centre for Competence in Research - Molecular Systems Engineering (NCCR-MSE). We gratefully acknowledge the BioEM Lab, Dr. Mohamed Chami and Carola Alampi for the Cryogenic transmission electron microscopy measurements and useful discussions.

\section{Supporting Information Content}

- Example calculation of EHOx and EtOz block length by ${ }^{1} \mathrm{H}$ NMR and showcase of the remaining $A B C$ triblock synthetized not shown in this manuscript.

- Calculations of the length of the polymer segments (PEO, PEHOx) and their conformation.

- Extra TEM and Cryo-TEM images in higher resolution of the self-assembly of ABC triblocks. 
- Comparison of the ${ }^{1} \mathrm{H}$ NMR intensity from PEO versus PEHOx+PEtOz in asymmetric and mixed $\mathrm{A}+\mathrm{C}$ polymersomes.

\section{Notes}

The authors declare no competing financial interests.

\section{References:}

1. Allen, T. M.; Cullis, P. R., Drug Delivery Systems: Entering the Mainstream. Science 2004, 303 (5665), 1818-1822.

2. Deraedt, C.; Astruc, D., Supramolecular nanoreactors for catalysis. Coordination Chemistry Reviews 2016, 324, 106-122.

3. Gaitzsch, J.; Huang, X.; Voit, B., Engineering Functional Polymer Capsules toward Smart Nanoreactors. Chemical Reviews 2016, 116 (3), 1053-1093.

4. Belluati, A.; Craciun, I.; Liu, J.; Palivan, C. G., Nanoscale Enzymatic Compartments in Tandem Support Cascade Reactions in Vitro. Biomacromolecules 2018, 19 (10), 4023-4033.

5. Thamboo, S.; Najer, A.; Belluati, A.; von Planta, C.; Wu, D.; Craciun, I.; Meier, W.; Palivan, C. G., Mimicking Cellular Signaling Pathways within Synthetic Multicompartment Vesicles with Triggered Enzyme Activity and Induced Ion Channel Recruitment. Advanced Functional Materials 2019, 29 (40), 1904267.

6. Palivan, C. G.; Goers, R.; Najer, A.; Zhang, X.; Car, A.; Meier, W., Bioinspired polymer vesicles and membranes for biological and medical applications. Chemical Society Reviews 2016, 45 (2), 377 411.

7. Folini, J.; Huang, C.-H.; Anderson, J. C.; Meier, W. P.; Gaitzsch, J., Novel monomers in radical ring-opening polymerisation for biodegradable and $\mathrm{pH}$ responsive nanoparticles. Polymer Chemistry 2019, 10 (39), 5285-5288.

8. Zhao, L.; Li, N.; Wang, K.; Shi, C.; Zhang, L.; Luan, Y., A review of polypeptide-based polymersomes. Biomaterials 2014, 35 (4), 1284-1301.

9. Pawar, P. V.; Gohil, S. V.; Jain, J. P.; Kumar, N., Functionalized polymersomes for biomedical applications. Polymer Chemistry 2013, 4 (11), 3160-3176.

10. Belluati, A.; Mikhalevich, V.; Yorulmaz Avsar, S.; Daubian, D.; Craciun, I.; Chami, M.; Meier, W. P.; Palivan, C. G., How Do the Properties of Amphiphilic Polymer Membranes Influence the Functional Insertion of Peptide Pores? Biomacromolecules 2020, 21 (2), 701-715.

11. Rothman, J.; Lenard, J., Membrane asymmetry. Science 1977, 195 (4280), 743-753.

12. Rigaud, J. L.; Paternostre, M. T.; Bluzat, A., Mechanisms of membrane protein insertion into liposomes during reconstitution procedures involving the use of detergents. 2. Incorporation of the light-driven proton pump bacteriorhodopsin. Biochemistry 1988, 27 (8), 2677-2688.

13. Buch-Pedersen, M. J.; Pedersen, B. P.; Veierskov, B.; Nissen, P.; Palmgren, M. G., Protons and how they are transported by proton pumps. Pflügers Archiv - European Journal of Physiology 2008, 457 (3), 573.

14. Pautot, S.; Frisken, B. J.; Weitz, D. A., Engineering asymmetric vesicles. Proceedings of the National Academy of Sciences 2003, 100 (19), 10718-10721. 
15. Mason, A. F.; Thordarson, P., Polymersomes with Asymmetric Membranes Based on Readily Accessible Di- and Triblock Copolymers Synthesized via SET-LRP. ACS Macro Letters 2016, 5 (10), 1172-1175.

16. Goers, R.; Thoma, J.; Ritzmann, N.; Di Silvestro, A.; Alter, C.; Gunkel-Grabole, G.; Fotiadis, D.; Müller, D. J.; Meier, W., Optimized reconstitution of membrane proteins into synthetic membranes. Communications Chemistry 2018, 1 (1), 35.

17. Konishcheva, E. V.; Zhumaev, U. E.; Meier, W. P., PEO-b-PCL-b-PMOXA Triblock Copolymers: From Synthesis to Microscale Polymersomes with Asymmetric Membrane. Macromolecules 2017, 50 (4), 1512-1520.

18. Konishcheva, E. V.; Daubian, D.; Rigo, S.; Meier, W. P., Probing membrane asymmetry of ABC polymersomes. Chemical Communications 2019, 55 (8), 1148-1151.

19. Stoenescu, R.; Meier, W., Vesicles with asymmetric membranes from amphiphilic ABC triblock copolymers. Chemical Communications 2002, (24), 3016-3017.

20. Stoenescu, R.; Graff, A.; Meier, W., Asymmetric ABC-triblock copolymer membranes induce a directed insertion of membrane proteins. Macromol Biosci 2004, 4 (10), 930-5.

21. Gaitzsch, J.; Hirschi, S.; Freimann, S.; Fotiadis, D.; Meier, W., Directed Insertion of LightActivated Proteorhodopsin into Asymmetric Polymersomes from an ABC Block Copolymer. Nano Letters 2019, 19 (4), 2503-2508.

22. He, X.; Liang, L.; Xie, M.; Zhang, Y.; Lin, S.; Yan, D., Synthesis of Novel Linear PEO-b-PS-b-PCL Triblock Copolymers by the Combination of ATRP, ROP, and a Click Reaction. Macromolecular Chemistry and Physics 2007, 208 (16), 1797-1802.

23. Lobling, T. I.; Borisov, O.; Haataja, J. S.; Ikkala, O.; Groschel, A. H.; Muller, A. H., Rational design of $A B C$ triblock terpolymer solution nanostructures with controlled patch morphology. Nat Commun 2016, 7, 12097.

24. Bian, J.; Hao, Y.; He, J.; Zhang, W.; Zhang, M.; Ni, P., Synthesis and characterization of a biodegradable $A B C$ triblock terpolymer as co-delivery carrier of doxorubicin and DNA. Journal of Polymer Science Part A: Polymer Chemistry 2014, 52 (21), 3005-3016.

25. Wittemann, A.; Azzam, T.; Eisenberg, A., Biocompatible Polymer Vesicles from Biamphiphilic Triblock Copolymers and Their Interaction with Bovine Serum Albumin. Langmuir 2007, 23 (4), 22242230.

26. Konishcheva, E.; Daubian, D.; Gaitzsch, J.; Meier, W., Synthesis of Linear ABC Triblock Copolymers and Their Self-Assembly in Solution. Helvetica Chimica Acta 2018, 101 (2), e1700287.

27. Kempe, K.; Baumgaertel, A.; Hoogenboom, R.; Schubert, U. S., Design of new amphiphilic triblock copoly(2-oxazoline)s containing a fluorinated segment. Journal of Polymer Science Part A: Polymer Chemistry 2010, 48 (22), 5100-5108.

28. Kempe, K.; Hoogenboom, R.; Hoeppener, S.; Fustin, C.-A.; Gohy, J.-F.; Schubert, U. S., Discovering new block terpolymer micellar morphologies. Chemical Communications 2010, 46 (35), 6455-6457.

29. Hoogenboom, R.; Wiesbrock, F.; Leenen, M. A. M.; Thijs, H. M. L.; Huang, H.; Fustin, C.-A.; Guillet, P.; Gohy, J.-F.; Schubert, U. S., Synthesis and Aqueous Micellization of Amphiphilic Tetrablock Ter- and Quarterpoly(2-oxazoline)s. Macromolecules 2007, 40 (8), 2837-2843.

30. Daubian, D.; Gaitzsch, J.; Meier, W., Synthesis and complex self-assembly of amphiphilic block copolymers with a branched hydrophobic poly(2-oxazoline) into multicompartment micelles, pseudo-vesicles and yolk/shell nanoparticles. Polymer Chemistry 2020, 11 (6), 1237-1248.

31. Kempe, K.; Jacobs, S.; Lambermont-Thijs, H. M. L.; Fijten, M. M. W. M.; Hoogenboom, R.; Schubert, U. S., Rational Design of an Amorphous Poly(2-oxazoline) with a Low Glass-Transition Temperature: Monomer Synthesis, Copolymerization, and Properties. Macromolecules 2010, 43 (9), 4098-4104.

32. Hotz, J.; Meier, W., Vesicle-Templated Polymer Hollow Spheres. Langmuir 1998, 14 (5), 1031-1036. 
33. Egelhaaf, S. U.; Schurtenberger, P., Shape Transformations in the Lecithin-Bile Salt System: From Cylinders to Vesicles. The Journal of Physical Chemistry 1994, 98 (34), 8560-8573.

34. Wehr, R.; Gaitzsch, J.; Daubian, D.; Fodor, C.; Meier, W., Deepening the insight into poly(butylene oxide)-block-poly(glycidol) synthesis and self-assemblies: micelles, worms and vesicles. RSC Advances 2020, 10 (38), 22701-22711.

35. Liu, G.; Ma, S.; Li, S.; Cheng, R.; Meng, F.; Liu, H.; Zhong, Z., The highly efficient delivery of exogenous proteins into cells mediated by biodegradable chimaeric polymersomes. Biomaterials 2010, 31 (29), 7575-7585.

36. Schlaad, H.; You, L.; Sigel, R.; Smarsly, B.; Heydenreich, M.; Mantion, A.; Mašić, A., Glycopolymer vesicles with an asymmetric membrane. Chemical Communications 2009, (12), 14781480. 